Research Article

\title{
Implications of Contract-Bargaining Mechanisms for Coordination and Profit Sharing in a Distribution Channel
}

\author{
Nikunja Mohan Modak $\mathbb{D}^{1},{ }^{1}$ Shibaji Panda $\mathbb{D}^{2},{ }^{2}$ Sudipta Sinha $\mathbb{D}^{3}{ }^{3}$ and Dipankar Ghosh ${ }^{4}$ \\ ${ }^{1}$ Palpara Vidyamandir, Chakdaha-741222, West Bengal, India \\ ${ }^{2}$ Department of Controller of Examinations, Bankura University, P.O. Purandarpur, Bankura 722155, West Bengal, India \\ ${ }^{3}$ Department of Mathematics, Burdwan Raj College, University of Burdwan, Burdwan, West Bengal 713104, India \\ ${ }^{4}$ Department of Electronics \& Communication Engineering, Future Institute of Engineering \& Management, \\ Sonarpur Station Road, Kolkata 700150, West Bengal, India
}

Correspondence should be addressed to Nikunja Mohan Modak; nikunja.modak@gmail.com

Received 22 April 2021; Accepted 28 June 2021; Published 8 July 2021

Academic Editor: Francesco Lolli

Copyright (c) 2021 Nikunja Mohan Modak et al. This is an open access article distributed under the Creative Commons Attribution License, which permits unrestricted use, distribution, and reproduction in any medium, provided the original work is properly cited.

\begin{abstract}
The present work models a three-level distribution channel that has a manufacturer, multiple distributors, and multiple retailers under each distributor to analyze channel members' cooperative, semicooperative, and noncooperative decisions for an arbitrary replenishment cycle other than the first in the infinite time horizon. It uses two sequential bargaining processes: forward contractbargaining (FCB) and backward contract-bargaining (BCB) to eliminate channel conflict and allocate additional profit among channel members. We successfully implement a hybrid contract mechanism that combines wholesale price discount (WPD) and subsidy on holding cost for channel coordination. The concept of Nash bargaining is applied for additional profit sharing. The proposed hybrid contract can fully coordinate the tree-like supply chain and enrich the entire profit of the supply chain at its best. The manufacturer provides WPD to each distributor separately, and each distributor provides a subsidy to each of its retailers independently. Both the sequential bargaining processes are designed in such a way that an upstream channel member always has the opportunity to account for different reservations for its different downstream members. Although each bargaining process eliminates the channel conflict, finds win-win ranges, and distributes surplus profit, the distributors prefer BCB, whereas the manufacturer and the retailers prefer the FCB. Also, without receiving WPD, the distributors have the ability to coordinate the supply chain and find win-win profits by subsidizing the retailers' holding costs. A numerical case is presented to explain the findings of the work.
\end{abstract}

\section{Introduction}

With increasing competitive pressures and market globalization the relation among a manufacturer, multiple distributors and multiple retailers of a three-stage conventional distribution channel have undergone enormous changes. When three stages are managed independently, the solution becomes suboptimal because of the differing self-regarding purposes of the channel participants [1]. So, coordination is vital for enhancing profit of the distribution channel $[2,3]$. With supply chain coordination, some channel members are impelled to accept some side-payment contracts offered by some other channel members in such a way that objectives of all participants will be aligned with the finest channel performance [4]. Several classes of coordination contract are used in the literature of supply chain. The coordination contracts the literature found in this regards are vast, and some of these are quantity discount [2], price discounts [5], revenue sharing [6], two-part tariff [7], etc. In reality, it is tougher to coordinate a three-echelon distribution channel with multiple members in some echelons by using a coordination contract as dimension of the solution space increase. It is required to coordinate the channel both vertically and horizontally to get the best performance [2].

Ganeshan [8] analyzed a three-echelon supply chain, where many suppliers supply goods to numerous retailers 
through single distributor. Khouja [9] modeled a three-stage supply chain, where at each stage there are several members. Ben-Daya and Al-Nassar [10] extended Khouja's [9] work based on a new assumption that lot-shipment between two different stages can be made before sale of an entire lot is ended. Khouja [11] developed an optimal synchronization algorithm for the management and incentive alignment along the each stage of supply chain. Cardenas-Barron [12] extended the work of Khouja [11] by assuming an $n$-stagemulti-customer inventory distribution channel. Jaber and Goyal [13] examined the problem of order quantity synchronization in a many buyers-one manufacturer-many retailers supply chain. Jonrinaldi and Zhang [14] considered a multiplayer multiechelon distribution channel and reverse logistics to find the best decisions over a restricted time horizon. In this direction, works of Sana [15], Pal et al. $[16,17]$, and Crdenas-Barrn and Sana [18] are worth mentioning.

Bargaining states the opportunities where two or more players can get win-win profit in a different manner through collaboration. In reality, bargaining is not only means a relationship among the participants but also involves negotiation over the trade contracts $[19,20]$. More than three decades ago, Kohli and Park [21] used the concept of bargaining in a buyer-seller supply chain in an EOQ setting. They investigated how the buyer and the seller negotiate to get mutual benefit over the amount of quantity discount. Several research works used Nash bargaining solution to maximize channel members expected utility functions $[19,20,22]$. Nagarajan and Sošić [23] reviewed basics of cooperative bargaining models in supply chain. Strategic behaviour of the channel members plays an important role to determine interactions among them and determine optimal decisions under different game theoretical perspectives [24-27].

This paper considers a distribution channel consisting of single manufacturer, many distributors, and several retailers corresponding to every distributor. The channel works in an infinite time horizon. A replenishment cycle apart from the first is considered in the modeling, and analysis of the first replenishment cycle is derived independently. Besides exploring centralized, semicentralized, and decentralized decisions, the major aim of the paper is to find the channel best solution by applying a hybrid contract. The hybrid contract involves wholesale price discount (WPD) that the manufacturer offers to each distributor separately and subsidy on holding cost, in which the distributors provide to their retailers independently. Also, the concept of Nash bargaining is used to allocate the additional profit among the channel participants.

Present work contributes to the literature differing from the previous research works are as follows. Firstly, it models a three-level distribution channel to analyze channel members cooperative, semicooperative, and noncooperative decisions for an arbitrary replenishment cycle other than the first in the infinite time horizon. Secondly, unlike earlier models, a hybrid coordination contract is used for channel coordination. The manufacturer provides different WPDs to different distributors. Also the subsidies on holding cost are dissimilar for different retailers. In the literature of multiechelon multimember supply chain, coordination contracts were not exclusively implemented to get the best channel performance. Most of these models assumed that members are cooperative and approved to implement centralized decisions. However, those models are failed to address every channel members' win-win profit simultaneously $[13,14]$. Thirdly, the win-win ranges for every member of the distribution channel are determined analytically in closed forms. Fourthly, the distributors play a key role in channel coordination and in distribution of surplus profit. When coordination contract and bargaining are applied, channel members' profits depend on the sequence of applications of these on the channel members. Standard practice in marketing demonstrates that the coordination and profit division are settled between two members, one each in two different stages at a time rather than among all the stages and all the members of a supply chain simultaneously. Also, each upstream channel member has diverse arrangement for each of its corresponding downstream channel member. Thus, an upstream member contracts with each of its downstream members individualistically. To implement coordination contract and bargaining, the paper suggests, namely, forward contract-bargaining (FCB) and backward contract-bargaining (BCB). In FCB, first each distributor and each of its corresponding retailer identify the range of subsidy on holding cost that provides win-win opportunities. Within this range, they settle for a particular subsidy through bargaining. Based on the bargaining outcome, each distributor and the manufacturer find the win-win range for WPD. Finally, the manufacturer bargains with each distributor for the specific WPD that shares the surplus profit. The same coordination contracts and bargaining are applied but in reverse order in BCB process. The procedures are nested because the outcome of the later coordination contract and bargaining are completely dependent on the outcome of the former contract and bargaining.

We use quantitative mathematical modeling for research development. Two nested contract-bargaining procedures along with an iterative method are introduced to find the optimal solution. Finally, analytical findings are examined through numerical simulation. The next section of the paper discusses decentralized, semicentralized, and centralized models. Channel coordination using contract mechanisms and profit distribution using bargaining are analyzed. Section 3 demonstrates a numerical illustration to verify analytical findings of the model. Finally, Section 4 summarizes the model outcomes and proposed various future research possibilities.

\section{Model Description and Basic Analysis}

The following notations are used in developing the model: The $i j$ th $\left(i=1,2, \ldots, n_{j} ; j=1,2, \ldots, n\right)$ retailer

$D_{i j}^{r}$ : demand rate in the decentralized model $h_{i j}^{r}$ : holding cost per unit per unit time including interest

$s_{i j}^{r}$ : setup cost per cycle 
$\pi_{i j}^{r}$ : profit function in the decentralized model

$\pi^{\text {rs }}$ : profit function of all retailers' in the semicentralized model

$\pi_{i j}^{\mathrm{rc}}$ : profit function in the centralized model

$T_{i j}^{r}$ : cycle length in the decentralized model

$T^{s}$ : cycle length of all retailers' in the semicentralized model

$Q_{i j}^{r}$ : order quantity of in the decentralized model

$Q_{i j}^{\text {rs: }}$ order quantity retailer in the semicentralized model

$Q_{i j}^{\text {rcc }}$ order quantity retailer in the centralized model

$p^{r}$ : unit product selling price to the customer

The $j$ th $(j=1,2, \ldots, n)$ distributor

$D_{j}^{d}$ : demand rate

$h_{j}^{d}$ : holding cost per unit per unit time including interest

$s_{j}^{d}$ : setup cost per cycle

$w^{d}$ : unit product wholesale price

$\pi_{j}^{d}$ : profit function in the decentralized model

$\pi^{\mathrm{ds}}$ : profit function of all distributors' in the semicentralized model

$\pi_{j}^{\mathrm{dc}}$ : profit function in the centralized model

$T_{j}^{d}$ : cycle length in the decentralized model

$Q_{j}^{d}$ : order quantity in the decentralized model

$Q_{j}^{\mathrm{dc}}$ : order quantity in the centralized model

The manufacturer

$D^{m}$ : demand rate

$h^{m}$ : holding cost per unit per unit time including interest

$s^{m}$ : setup cost per cycle.

$w^{m}:$ unit product wholesale price

$c^{m}:$ manufacturer's production cost

$\pi^{m}$ : profit function in the decentralized model

$\pi^{\mathrm{ms}}$ : profit function in the semicentralized model

$\pi^{\mathrm{mc}}$ : profit function in the centralized model

$T^{m}$ : cycle length in the decentralized model

$\mathrm{Q}^{m}$ : order quantity in the decentralized model

$Q^{\mathrm{mc}}$ : order quantity in the centralized model

$\alpha$ : integer multiple of cycle time for the distributors

$\beta$ : integer multiple of cycle time for the manufacturer

$\lambda_{i j}$ : percentage of compensation on holding cost (PCHC) of the $i j$ th retailer provided by the $j$ th distributor

$\lambda_{i j}$ : lower limit of PCHC

$\overline{\lambda_{i j}^{b}}$ : upper limit of PCHC in BCB

$\overline{\lambda_{i j}^{f}}$ : upper limit of PCHC in FCB

$\lambda_{i j}^{b}$ : bargaining $\mathrm{PCHC}$ in $\mathrm{BCB}$ $\lambda_{i j}^{f}$ : bargaining $\mathrm{PCHC}$ in FCB

$\rho_{j}$ : wholesale price discount (WPD) that the manufacturer provides to its $j$ th distributor

$\overline{\rho_{j}}$ : upper limit of WPD

$\rho_{j}^{b}$ : lower limit of WPD in BCB

$\overline{\rho_{j}^{f}}$ : lower limit of WPD in FCB

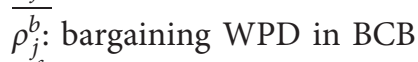

$\rho_{j}^{f}$ : bargaining WPD in FCB

Consider a conventional three-stage supply chain consisting of single manufacturer, multiple distributors, and multiretailer associated with each distributor. The channel operates in an infinite time horizon, and we consider an arbitrary replenishment cycle other than the first. The channel structure is depicted in Figure 1.

The manufacturer produces and supplies a product to $n$ distributors. The $j$ th distributor $(j=1,2, \ldots, n)$ transfers the product to its $n_{i j}\left(i=1,2, \ldots, n_{j}\right)$ number of retailers and the retailers sell the product to customers and fulfill the channel demand. Thus, there is $\sum_{j=1}^{n} \sum_{i=1}^{n_{j}} n_{i j}$ number of retailers in the channel. Assume that each of $n_{i j}\left(i=1,2, \ldots, n_{j} ; j=\right.$ $1,2, \ldots n)$ retailers faces deterministic demand $D_{i j}^{r}(i=1,2$, $\left.\ldots, n_{j} ; j=1,2, \ldots n\right)$ per unit time. The manufacturer produces the product at a unit cost $c^{m}$ and sales it to the distributors at a wholesale price $w^{m}$. Each distributor supplies the product to its retailers at a price $w^{d}$, and retailers sell the product to end customer at a price $p_{r}$. The present model has following limitations: a particular retailer can place order to a particular distributor, who is associated with it; that is, for each retailer, there is only one available distributor. Shortages are not allowed. No lead times are considered as the end customer's demand is assumed as constant.

2.1. Decentralized Decision-Making Process. In decentralized structure, members pay no attention to overall performance of the channel. Each member of the channel maximizes own profit function. Retailers first decide their individual order quantities and order cycle lengths. Obtaining responses from its retailers, a distributor finalizes its decision. Finally, the manufacturer makes decision based on the distributor's decisions. Decentralized order quantities of the manufacturer and the distributors in a replenishment cycle are structurally different from the order quantities of the first-order cycle. Initially, the manufacturer produces large amount of inventories to satisfy all the distributors' orders and to avoid stock out or late deliveries. Similarly, in the first-order cycle, a distributor's order quantity consists of initial orders from all of its retailers and safety stock $[14,28,29]$. After the first replenishment cycle, all the replenishment cycles are identical because an upstream channel member already carries safety stock to prevent stock out and it only bears holding cost corresponding to the safety stock. However, the retailers have no such responsibility. We explore the channel members' decisions in the initial-order cycle as well as in any one of the other identical order cycles. 


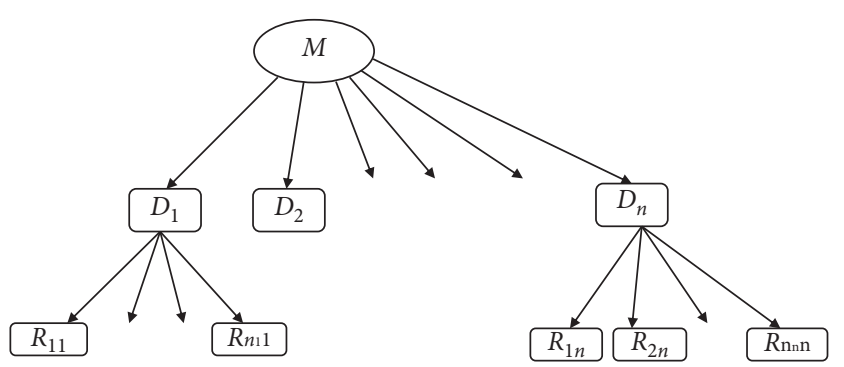

FIGURE 1: Structure of the distribution channel.

2.1.1. Retailers' Decisions. In a replenishment cycle, the $i j$ th retailer's $\left(i=1,2, . ., n_{j}: j=1,2, . ., n\right)$ inventory level decreases from the initial level $Q_{i j}^{r / d s}$ at the rate $D_{i j}^{r}$ and it reaches to zero level after time $T_{i j}^{r / d s}$. Then, the next replenishment cycle starts because of no shortage situation. The average profit of the $i j$ th retailer is $\pi_{i j}^{r / d s}=$ (sales revenue-purchase costholding cost-setup cost) per unit time and can be found as

$$
\pi_{i j}^{r / \mathrm{d} s}=\left(p^{r}-w^{d}\right) D_{i j}^{r}-\frac{s_{i j}^{r}}{T_{i j}^{r / \mathrm{ds}}}-\frac{h_{i j}^{r} D_{i j}^{r} T_{i j}^{r / \mathrm{d} s}}{2} .
$$

The necessary condition $\mathrm{d} \pi_{i j}^{r / \mathrm{d} s} / \mathrm{d} T_{i j}^{r / \mathrm{d} s}=0$ for existence of optimal solution yields

$$
T_{i j}^{r / \mathrm{ds}}=\sqrt{\frac{2 s_{i j}^{r}}{h_{i j}^{r} D_{i j}^{r}} .}
$$

Moreover,

$$
\frac{\mathrm{d}^{2} \pi_{i j}^{r / \mathrm{ds}}}{\mathrm{d} T_{i j}^{r / \mathrm{ds}}}=-\frac{2 s_{i j}^{r}}{\left(T_{i j}^{r / \mathrm{ds}}\right)^{3}}<0 .
$$

Therefore, $\pi_{i j}^{r / d s}$ is a concave function of $T_{i j}^{r / \mathrm{ds}}$ and equation (1) provides global optimum. Substituting optimal value of $T_{i j}^{r}$ in equation (1), the average optimal decentralized profit and optimal order quantity of the $i j$ th retailer are, respectively, as

$$
\begin{aligned}
& \pi_{i j}^{r / \mathrm{ds}}=\left(p^{r}-w^{d}\right) D_{i j}^{r}-\sqrt{2 s_{i j}^{r} h_{i j}^{r} D_{i j}^{r}}, \\
& Q_{i j}^{r / \mathrm{ds}}=D_{i j}^{r} T_{i j}^{r / \mathrm{ds}}=\sqrt{\frac{2 D_{i j}^{r} s_{i j}^{r}}{h_{i j}^{r}} .}
\end{aligned}
$$

2.1.2. Distributors' Decisions. The $j$ th, $(j=1,2,3, \ldots, n)$ distributor has $n_{i j}$ retailers. In the first replenishment cycle, it satisfies the demand at an average rate $D_{j}^{d}=\sum_{i=1}^{n_{j}} D_{i j}^{r}$. Since the channel members operate independently, the distributor carries a safety stock in such a way that it can satisfy all of its corresponding retailers' demand simultaneously. Failing to it, the distributor will suffer stock out or late deliveries as stated in the studies of Chan and Kingsman [28], Chan et al. [29], and Jonrinaldi and Zhang [14]. The largest possible aggregate order quantity of all the retailers under the $j$ th distributor is $\sum_{i=1}^{n_{j}} Q_{i j}^{r / d s}$. The optimal first replenishment cycle length and optimal order quantity in the first cycle of the $j$ th distributor are, respectively, as (see Appendix A)

$$
\begin{aligned}
& T_{j}^{d 1}=\sqrt{\frac{2\left[s_{j}^{d}+w^{m} \sum_{i=1}^{n_{j}} Q_{i j}^{r / \mathrm{ds}}\right]}{h_{j}^{d} D_{j}^{d}}}, \quad j=1,2, \ldots, n, \\
& Q_{j}^{d 1}=\sum_{i=1}^{n_{j}} Q_{i j}^{r / d s}+\sqrt{\frac{2\left[s_{j}^{d}+w^{m} \sum_{i=1}^{n_{j}} Q_{i j}^{r / d s}\right] D_{j}^{d}}{h_{j}^{d}}}, \quad j=1,2, \ldots, n .
\end{aligned}
$$

Apart from the first replenishment cycle, all the other cycles in the infinite time horizon are identical. Now, we consider a replenishment cycle in the infinite time horizon other than the first. The $j$ th distributor has no need to replenish the safety stock as it is already in hand. In the initial stage at the beginning of order cycle, products at distributors will be immediately used to satisfy the first order from retailers, but for the other replenishment cycles, there is no guarantee that all the retailers demand orders from its distributor at the beginning. So, the $j$ th $(j=1,2, . ., n)$ distributor's general stock will be $T_{j}^{d} D_{j}^{d}$. Thus, the average profit function of the $j$ th distributor can be found as

$$
\begin{aligned}
\pi_{j}^{d / \mathrm{ds}}= & \left(w^{d}-w^{m}\right) D_{j}^{d}-\frac{s_{j}^{d}}{T_{j}^{d / \mathrm{ds}}} \\
& -h_{j}^{d} \sum_{i=1}^{n_{j}} Q_{i j}^{r / \mathrm{ds}}-\frac{h_{j}^{d} T_{j}^{d / \mathrm{ds}} D_{j}^{d}}{2}, \quad j=1,2, \ldots, n .
\end{aligned}
$$

Differentiating $\pi_{j}^{d / \mathrm{ds}}$ with respect to $T_{j}^{d / \mathrm{ds}}$ and equating to zero the optimal cycle length of the $j$ th distributor is found as

$$
T_{j}^{d / \mathrm{ds} s}=\sqrt{\frac{2 s_{j}^{d}}{h_{j}^{d} D_{j}^{d}}}, \quad j=1,2, \ldots, n .
$$

Moreover,

$$
\frac{\mathrm{d}^{2} \pi_{j}^{\mathrm{d} / \mathrm{ds}}}{\mathrm{d} T_{j}^{\mathrm{d} / \mathrm{ds} s^{2}}}=-\frac{2 s_{j}^{d}}{\left(T_{j}^{\mathrm{d} / \mathrm{ds}}\right)^{3}}<0 .
$$

Thus, $T_{j}^{\mathrm{d} / \mathrm{ds}}$ provides global optimum. The optimal order quantity and optimal average profit of the $j$ th distributor are 


$$
\begin{aligned}
Q_{j}^{d / \mathrm{ds}}= & D_{j}^{d} T_{j}^{d / \mathrm{ds}}=\sqrt{\frac{2 D_{j}^{d} s_{j}^{d}}{h_{j}^{d}}}, \quad j=1,2, \ldots, n, \\
\pi_{j}^{d / \mathrm{ds}}= & \left(w^{d}-w^{m}\right) D_{j}^{d}-\frac{s_{j}^{d}}{T_{j}^{d / \mathrm{ds}}} \\
& -h_{j}^{d} \sum_{i=1}^{n_{j}} Q_{i j}^{r / \mathrm{ds}}-\frac{h_{j}^{d} T_{j}^{d / \mathrm{ds}} D_{j}^{d}}{2}, \quad j=1,2, \ldots, n .
\end{aligned}
$$

2.1.3. Manufacturer's Decision. The manufacturer faces orders from all the distributors. So, the demand at the manufacturer's end is $D^{m}=\sum_{j=1}^{n} \sum_{i=1}^{n_{j}} D_{i j}^{r}$. Similar to the first replenishment of a distributor, the optimal replenishment cycle length and order quantity of the manufacturer in the first replenishment cycle can be found as (see Appendix B)

$$
\begin{aligned}
T^{m *} & =\sqrt{\frac{2\left[s^{m}+c^{m} \sum_{j=1}^{n} Q_{j}^{d / d s}\right]}{h^{m} D^{m}}}, \\
Q^{m *} & =\sum_{j=1}^{n} Q_{j}^{d / \mathrm{ds}}+\sqrt{\frac{2\left[s^{m}+c^{m} \sum_{j=1}^{n} Q_{j}^{d / d s}\right] D^{m}}{h^{m}}} .
\end{aligned}
$$

Similar to the distributors, when the manufacturer wants to optimize its decisions after the first cycle, the decisions must be different from the initial one as the safety stock is already in hand. The manufacturer calculates its holding cost for an order cycle other than the initial one assuming that all the distributors must not demand their orders at the beginning of each replenishment cycle. Thus, the average profit function of the manufacturer is

$$
\pi^{m / \mathrm{ds}}=\left(w^{m}-c^{m}\right) D^{m}-\frac{s^{m}}{T^{m / \mathrm{ds}}}+h^{m} \sum_{j=1}^{n} Q_{j}^{d / \mathrm{ds}}-\frac{h^{m} T^{m / \mathrm{ds}} D^{m}}{2} .
$$

Using necessary condition, the optimal cycle length of the manufacturer can be found as

$$
T^{m / \mathrm{d} s}=\sqrt{\frac{2 s^{m}}{h^{m} D^{m}}}
$$

Moreover,

$$
\frac{\mathrm{d}^{2} \pi^{m g}}{\mathrm{~d} T^{m / \mathrm{ds}^{2}}}=-\frac{2 s^{m}}{\left(T^{m / \mathrm{ds}}\right)^{3}}<0 .
$$

Thus, the average profit function of the manufacturer given in equation (15) is a concave function of the cycle length of the manufacturer and equation (16) provides global optimum cycle length of the manufacturer. Optimal production lot and optimal average profit of the manufacturer are, respectively, as

$$
\begin{aligned}
& Q^{m / \mathrm{ds}}=D^{m} T^{m / \mathrm{ds}}=\sqrt{\frac{2 D^{m} s^{m}}{h^{m}}}, \\
& \pi^{m / \mathrm{ds}}=\left(w^{m}-c^{m}\right) D^{m}-\frac{s^{m}}{T^{m / \mathrm{ds}}}+h^{m} \sum_{j=1}^{n} Q_{j}^{d / \mathrm{ds}}-\frac{h^{m} T^{m / \mathrm{ds}} D^{m}}{2} .
\end{aligned}
$$

2.2. Semicentralized Decision-Making Process. When all participants in a certain stage of the supply chain agree to synchronize decisions of that stage, the situation refers to the semicentralized channel.

2.2.1. Horizontal Coordination among the Retailers. In decentralized channel, all the retailers operate independently. So, different retailers have different optimal order quantities and different replenishment cycles. As a result, anticipating any of its associated retailer's stock out, a distributor maintains a safety stock throughout the replenishment cycle. It incurs additional holding cost to the distributor. This situation can be avoided if the replenishment cycles of the retailers are synchronized, i.e., all the retailers opt for a common replenishment cycle $T^{s}$. In such case, a distributor does not need to carry the safety stock.

When all the retailers agree for a common replenishment cycle, average total profit of all the retailers is

$$
\pi^{r s}=\left(p^{r}-w^{d}\right) \sum_{j=1}^{n} \sum_{i=1}^{n_{j}} D_{i j}^{r}-\frac{\sum_{j=1}^{n} \sum_{i=1}^{n_{j}} s_{i j}^{r}}{T^{s}}-\frac{T^{s}}{2} \sum_{j=1}^{n} \sum_{i=1}^{n_{j}} h_{i j}^{r} D_{i j}^{r} .
$$

The necessary condition for the existence of optimal solution yields

$$
T^{s^{*}}=\sqrt{\left[\frac{2 \sum_{j=1}^{n} \sum_{i=1}^{n_{j}} s_{i j}^{r}}{\sum_{j=1}^{n} \sum_{i=1}^{n_{j}} h_{i j}^{r} D_{i j}^{r}}\right]} .
$$

The optimal order quantity of the ijth retailer can be found as

$$
Q_{i j}^{r s}=D_{i j}^{r} \sqrt{\left[\frac{2 \sum_{j=1}^{n} \sum_{i=1}^{n_{j}} s_{i j}^{r}}{\sum_{j=1}^{n} \sum_{i=1}^{n_{j}} h_{i j}^{r} D_{i j}^{r}}\right]}, \quad i=1,2, \ldots, n_{j} ; j=1,2, \ldots, n .
$$

Optimal average profit of the $i j$ th retailer can be found from equation (1) by substituting $T^{s *}$ for $T_{i j}^{r *}$.

Since, for $T_{i j}^{r / \mathrm{ds}}, \quad i j$ th retailer's, $i=1,2, \ldots, n_{j}$; $j=1,2, \ldots, n$ is maximum, any deviation of the replenishment cycle length leads to some profit loss of the retailer. So, when the retailers follow a common order cycle through synchronization, their profits will be less than their decentralized profits. 
2.2.2. Horizontal Coordination among the Distributors. In response to the synchronized decision of the retailers, suppose the distributors agree to synchronize their replenishment cycle lengths to a common one. Then, the distributor's common cycle length is an integer multiple, say $\alpha$ of $T^{s *}$ Thus, average total profit of all the distributors is

$$
\pi^{d s}=\left(w^{d}-w^{m}\right) \sum_{j=1}^{n} D_{j}^{d}-\frac{\sum_{j=1}^{n} s_{j}^{d}}{\alpha T^{s^{*}}}-\frac{(\alpha-1) T^{s^{*}}}{2} \sum_{j=1}^{n} h_{j}^{d} D_{j}^{d} .
$$

The distributors can perfectly anticipate the demands of the retailers. So, the distributors do not need to keep the safety stock to prevent stock outs as in the case of decentralized decision making. Also the distributors can use inventories immediately to satisfy the last order from the retailers in the replenishment cycle. Thus, the distributors maximum stock will be $D_{j}^{d}(\alpha-1) T^{s *}$. The holding cost of the distributors will be incurred in its average cost for the time $(\alpha-1) T^{s *}$. So, the average total profit of the distributors will be greater when compared with the decentralized decision.

2.2.3. Manufacturer's Decision. When there is stagewise synchronization in the first and second echelons of the supply chain, the manufacturer considers a common production cycle length that is an integer multiple of the common replenishment cycle length of the distributors, i.e., $\alpha \beta T^{r *}$, where $\beta$ is an integer. The profit function of the manufacturer per unit time is

$$
\pi^{m s}=\left(w^{m}-c^{m}\right) D^{m}-\frac{s^{m}}{\alpha \beta T^{s *}}-\frac{(\beta-1) \alpha T^{s *}}{2} h^{m} D^{m} .
$$

As in the case of the distributors, the manufacturer can anticipate the distributor's first-order quantity and does not need to carry any stocks for stock outs and/or late deliveries. The maximum stock of the manufacturer is $D^{m}(\beta-1) \alpha T^{s *}$. So, the manufacturer's profit is less compared to its decentralized profit.

From the above discussion of semicentralized decision making process, the following result can be realized.

Lemma 1. Stagewise coordination provides higher profits to the distributors and the manufacturer but lower profits to the retailers when compared with decentralized profits.

2.3. Centralized Decision. In centralized decision, members of the supply chain obey synchronized or integrated decisions to get maximum channel performance. It seems to be operated by a single decision maker who takes all the decisions in the distribution channel. The manufacturer, the distributors, and the retailers adopt a common cycle $T$. The manufacturer and the distributor follow lot-for-lot policy. Since the manufacturer and the distributors do not carry any inventory, the stock holding cost will be incurred in the retailers' profits only. Total profit of the channel per unit time is

$$
\begin{aligned}
\pi^{c}= & \left(p^{r}-c^{m}\right) \sum_{i=1}^{n_{j}} \sum_{j=1}^{n} D_{i j}^{r}-\frac{\sum_{i=1}^{n_{j}} \sum_{j=1}^{n} s_{i j}^{r}+\sum_{j=1}^{n} s_{j}+s_{m}}{T} \\
& -\frac{T}{2} \sum_{i=1}^{n_{j}} \sum_{j=1}^{n} h_{i j}^{r} D_{i j}^{r} .
\end{aligned}
$$

Necessary condition for the existence of optimal solution yields the common cycle length of the channel is

$$
T^{*}=\sqrt{\frac{2\left(\sum_{i=1}^{n_{j}} \sum_{j=1}^{n} s_{i}^{r}+\sum_{j=1}^{n} s_{j}^{d}+s^{m}\right)}{\sum_{i=1}^{n_{j}} \sum_{j=1}^{n} h_{i j}^{r} D_{i j}^{r}} .}
$$

Moreover,

$$
\frac{\mathrm{d}^{2} \pi^{c}}{\mathrm{~d} T^{2}}=-\frac{2\left(\sum_{i=1}^{n_{j}} \sum_{j=1}^{n} s_{i j}^{r}+\sum_{j=1}^{n} s_{j}^{d}+s^{m}\right)}{(T)^{3}}<0 .
$$

Hence, equation (26) provides the global optimal solution of equation (25).

The optimal order quantities and optimal average profits of the $i j$ th retailer, the $j$ th distributor, and the manufacturer are, respectively, as

$$
Q_{i j}^{r * *}=D_{i j}^{r} T^{*}, \quad i=1,2, \ldots, n_{j} ; j=1,2, \ldots, n,
$$

$Q_{j}^{d c *}=\sum_{i=1}^{n_{j}} D_{i j}^{r} T^{*}, \quad j=1,2, \ldots, n$,

$Q^{m c *}=\sum_{i=1}^{n^{j}} \sum_{j=1}^{n} D_{i j}^{r} T^{*}$

$\pi_{i j}^{r c *}=\left(p^{r}-w^{d}\right) D_{i j}^{r}-\frac{s_{i j}^{r}}{T^{*}}-\frac{h_{i j}^{r} D_{i j}^{r} T^{*}}{2}, \quad i=1,2, \ldots, n_{j} ; j=1,2, \ldots, n$,

$\pi_{j}^{d c *}=\left(w^{d}-w^{m}\right) D_{j}^{d}-\frac{s_{j}^{d}}{T^{*}}, \quad j=1,2, \ldots, n$,

$\pi^{m c *}=\left(w^{m}-c^{m}\right) D^{m}-\frac{s^{m}}{T^{*}}$.

The optimal total profit of the centralized channel is maximum when compared with the semicentralized or decentralized channel $[13,14,28,29]$. Since, the manufacturer and the distributors do not have stock holding cost, and their profits are greater than their semicentralized as well as decentralized profits. So, the manufacturer and the distributors prefer centralized decisions. However, $\pi_{i j}^{\mathrm{rs} *}-\pi_{i j}^{\mathrm{rc} *}<0,\left(i=1,2, \ldots, n_{j} ; j=1,2, \ldots, n\right)$, i.e., the 
retailer's profit is less than decentralized decision making. Thus, we have the following lemma.

Lemma 2. The centralized profits of the retailers' are lower, whereas the distributors and the manufacturers are higher in centralized decision when compared with semicentralized decision.

From the above discussion, we have the results displayed in Table 1.

Therefore, from Lemmas 1 and 2, and Table 1, we have the following proposition.

Proposition 1. In a conventional three-echelon distribution channel, the retailers' profits are minimum but the distributors' and the manufacturer's profits are maximum for centralized decision.

\section{Channel Coordination, Ranges of Win-Win Opportunities, and Surplus Profit Division}

When centralized decisions are implemented, upstream channel members (the manufacturer and the distributors) follow lot-for-lot policy and their holding costs are zero. On the other hand, holding cost of the retailers increases significantly. As a result, the retailers' profits in centralized decision are less compared to their decentralized profits. Thus, there is no reason that the retailers accept centralized decision. The retailers accept the centralized decision only when they receive some incentives, which ensure at least their decentralized profits. Assume that the distributors provide percentage subsidies on holding cost to each of their corresponding retailers to induce them to order centralized quantities. Because of incentives, the distributors' profits may be lower than their decentralized profits. So, to encourage the distributors, the manufacturer provides different wholesale price discounts to different distributors in such a way that it ensure each distributor's decentralized profit. In reality, an upstream member offers more amenities to those downstream members who have the ability to give more business. Thus, an upstream member affords different percentages of subsidies for its different downstream members independently. The amount of compensation an upstream member offers to a downstream member will depend on the amount of profit it gets from that downstream member's cooperation. In that case, a channel member assumes that there are no other echelon and no other members.

Note that, for channel synchronization, the distributors play a vital role as they maintain the lot streaming between the manufacturer and the retailers. Here, we propose two different approaches to encourage the distributors to play the key role for channel coordination. When one approaches from the manufacturer after satisfying its decentralized profit, a distributor receives some extra profit through negotiation. Decentralized profit plus the surplus profit share is the distributor's intermediate profit. Based on this profit, the distributor approaches to each of its corresponding retailers to provide minimum subsidy and to bargain for surplus share. When one approaches from the retailers, a distributor first compensates a retailer's loss of profit due to centralized order quantity and then bargains for surplus share. Obviously, in this case, the intermediate profit of a distributor is different from the other approach. Thus, there arise two cases, viz, (i) FCB process and (ii) BCB process.

3.1. FCB Process. The sequence of application of coordination contracts and bargaining among the channel members are as follows:

(1) The manufacturer considers each of its distributors separately and determines the WPD ranges for winwin profits.

(2) Within a wholesale price range, the manufacturer bargains with the corresponding distributor for a particular wholesale price discount for surplus profit share. The decentralized profit plus cumulative surplus profit shares from all the distributors is the manufacturer's optimal profit. The decentralized profit plus the surplus profit share is the distributor's intermediate profit.

(3) Based on this profit, a distributor identifies the ranges of percentage subsidy on holding costs corresponding to each of its retailers.

(4) Within a range, a distributor bargains with the corresponding retailer for subsidy fraction that determines surplus profit share. The decentralized profit plus surplus profit share is a retailer's optimal cost. Profit of step 2 plus cumulative surplus profit shares corresponding to all of its retailers is the distributor's optimal profit.

The manufacturer has $n$ distributors. The manufacturer considers its profit corresponding to each distributor separately and takes decision. So, the profit component of the manufacturer for $j$ th $(j=1,2, \ldots, n)$ distributor in the centralized channel and decentralized channel is, respectively, as

$$
\begin{gathered}
\pi_{j}^{\mathrm{mc}}=\frac{Q_{j}^{\mathrm{dc*}}}{Q^{\mathrm{mc*}}} \pi^{\mathrm{mc} *}, \quad j=1,2, \ldots, n, \\
\pi_{j}^{m / \mathrm{ds}}=\frac{T^{m / \mathrm{ds}} D_{j}^{d}}{Q^{m / \mathrm{ds}}} \pi^{m / \mathrm{ds}}, \quad j=1,2, \ldots, n .
\end{gathered}
$$

The manufacturer offers WPD to encourage a distributor for accepting centralized decision. The manufacturer can provide WPD to a particular distributor until its profit corresponding to that distributor is not less than corresponding decentralized profit. If the manufacturer gives the maximum $\overline{\rho_{j}}$ discount on wholesale price to the $j$ th distributor for accepting its centralized order quantity, then

$$
\left(\overline{\rho_{j}} w^{m}\right) Q_{j}^{\mathrm{dc} *}=\pi_{j}^{\mathrm{mc} *}-\pi_{j}^{m / \mathrm{ds}},
$$

i.e.,

$$
\overline{\rho_{j}}=\frac{\pi_{j}^{m c *}-\pi_{j}^{m / \mathrm{d} s}}{w^{m} Q_{j}^{\mathrm{dc} *}}, \quad j=1,2, \ldots, n .
$$


TABle 1: Comparison of channel members' profits in three decision-making scenarios.

\begin{tabular}{lccc}
\hline Profit & Decentralized & Semicentralized & Centralized \\
\hline Retailer & Highest & Medium & Lowest \\
Distributor & Lowest & Medium & Highest \\
Manufacturer & Lowest & Medium & Highest \\
\hline
\end{tabular}

Therefore, after providing maximum WPD to all the distributors, the manufacturer's profit will be exactly equal to its decentralized profit.

Similarly, if the $j$ th $(j=1,2, \ldots, n)$ distributor demands minimum $\rho_{j}^{f}\left(0 \leq \rho_{j}^{f} \leq 1\right)$ wholesale price discount from the manufacturer, then $\underline{\rho}_{j}^{f}$ can be found as

$$
\underline{\rho}_{j}^{f}=\frac{\pi_{j}^{d / \mathrm{ds}}-\pi_{j}^{\mathrm{dc} *}}{w^{m} D_{j}^{d}}, \quad j=1,2, \ldots, n .
$$

Thus, at this point for any $\rho_{j} \in\left(\rho_{j}^{f}, \overline{\rho_{j}}\right)$, the $j$ th $(j=1,2, \ldots, n)$ distributor's profit and the manufacturer's profit corresponding to the distributor are win-win.

Now, we use the Nash bargaining product to divide the surplus profit. In the Nash bargaining model, the objective function is the product of the player's gain from cooperation and it will have to be maximized. Each player's benefit is the difference between the negotiated profit and profit under decentralized decision making.

The Nash bargaining product of the manufacturer and the $j$ th $(j=1,2, \ldots, n)$ distributor can be found as

$$
\begin{aligned}
& \max _{\underline{\rho_{j}^{f}} \leq \rho_{j} \leq \overline{\rho_{j}}}\left[\pi_{j}^{\mathrm{dc} *}-\pi_{j}^{d / \mathrm{ds}}+\rho_{j} w^{m} D_{j}^{d}\right] \\
& {\left[\pi_{j}^{\mathrm{mc}}-\pi_{j}^{m / \mathrm{ds}}-\rho_{j} w^{m} D_{j}^{d}\right], \quad j=1,2, \ldots, n .}
\end{aligned}
$$

The optimal value of $\rho_{j}(j=1,2, \ldots, n)$ is

$$
\rho_{j}^{f}=\frac{\left(\pi_{j}^{m c}-\pi_{j}^{m / \mathrm{ds}}\right)-\left(\pi_{j}^{\mathrm{dc} *}-\pi_{j}^{d / \mathrm{ds}}\right)}{2 w^{m} D_{j}^{d}}, \quad j=1,2, \ldots, n .
$$

After settling benefit share with the manufacturer, the intermediate profit of the $j$ th $(j=1,2, \ldots, n)$ distributor becomes

$$
\pi_{j}^{\mathrm{df}}=\left(w^{d}-\left(1-\rho_{j}^{f}\right) w^{m}\right) D_{j}^{d}-\frac{s_{j}^{d}}{T^{*}}, \quad j=1,2, \ldots, n .
$$

The decrement of profit of the $i j$ th $\left(i=1,2, \ldots, n_{j} ; j=1,2, \ldots, n\right)$ retailer for accepting $Q_{i j}^{\mathrm{rc} *}$ instead of $Q_{i j}^{r / d s}$ is $\pi_{i j}^{\mathrm{rc} *}-\pi_{i j}^{r / \mathrm{ds}}$. As incentive, the $j$ th $(j=1,2, \ldots, n)$ distributor shares a percentage of holding cost to its associated $\left(i=1,2, \ldots, n_{j} ; j=1,2, \ldots, n\right)$ retailers. If $\lambda_{i j}\left(i=1,2, \ldots, n_{j} ; j=1,2, \ldots, n\right)$ is the minimum percent of holding cost that $j$ th distributor shares of its $i j$ th retailer, then

$$
\pi_{i j}^{r / \mathrm{ds}}-\pi_{i j}^{r c *}=\underline{\lambda_{i j}}\left[\frac{h_{i j}^{r} D_{i j}^{r} T^{*}}{2}\right], \quad i=1,2, \ldots, n_{j} ; j=1,2, \ldots, n .
$$

Thus, from equation (42), it follows that

$$
\underline{\lambda_{i j}}=\frac{2\left(\pi_{i j}^{r / \mathrm{ds}}-\pi_{i j}^{\mathrm{rc*}}\right)}{h_{i j}^{r} D_{i j}^{r} T^{*}} .
$$

Profit component of the $j$ th distributor $(j=1,2, \ldots, n)$ corresponding to the $i j$ th retailer is

$$
\pi_{i j}^{\mathrm{df}}=\frac{Q_{i j}^{\mathrm{rc} *}}{Q_{j}^{\mathrm{dc} *}} \pi_{j}^{\mathrm{df}}, \quad i=1,2, \ldots, n_{j} ; j=1,2, \ldots, n .
$$

Similarly, if the $j$ th $(j=1,2, \ldots, n)$ distributor provides maximum ${\overline{\lambda_{i j}}}^{f}\left(i=1,2, \ldots, n_{j} ; j=1,2, \ldots, n\right)$ compensation on holding cost to the ijth retailer, then ${\overline{\lambda_{i j}}}^{f}$ can be found as

$$
{\overline{\lambda_{i j}}}^{f}=\frac{2\left(\pi_{i j}^{\mathrm{df}}-\pi_{i j}^{d}\right)}{h_{i j}^{r} D_{i j}^{r} T^{*}} .
$$

Thus, for any $\lambda_{i j} \in\left(\lambda_{i j}, \bar{\lambda}_{i j}{ }^{f}\right)$, the $j$ th distributor and $i j$ th retailer achieve win-win profit. Now, if the distributor and the retailer bargain for a particular $\lambda_{i j}$ within this range, then the Nash bargaining product can be found as

$$
\begin{aligned}
& \max _{\underline{\lambda_{i j}} \leq \lambda_{i j} \leq \bar{\lambda}_{i j}^{f}}\left[\pi_{i j}^{r c *}-\pi_{i j}^{r / \mathrm{ds}}+\lambda_{i j}\left(\frac{h_{i j}^{r} D_{i j}^{r} T^{*}}{2}\right)\right] \\
& {\left[\pi_{i j}^{d f}-\pi_{i j}^{d}-\lambda_{i j}\left(\frac{h_{i j}^{r} D_{i j}^{r} T^{*}}{2}\right)\right], \quad i=1,2, \ldots, n_{j} ; j=1,2, \ldots, n .}
\end{aligned}
$$

Optimal value of $\lambda_{i j}$ is

$$
\lambda_{i j}^{f}=\frac{\pi_{i j}^{d f}-\pi_{i j}^{d}+\pi_{i j}^{r / \mathrm{ds}}-\pi_{i j}^{r c *}}{h_{i j}^{r} D_{i j}^{r} T^{*}}, \quad i=1,2, \ldots, n_{j} ; j=1,2, \ldots, n .
$$

Therefore, optimal profits of the retailers, the distributors, and the manufacturer are 


$$
\begin{aligned}
& \pi_{i j}^{\mathrm{rf} *}=\pi_{i j}^{r / \mathrm{ds}}+\frac{1}{2}\left[\left(\pi_{i j}^{\mathrm{df}}-\pi_{i j}^{d}\right)-\left(\pi_{i j}^{r / \mathrm{ds}}-\pi_{i j}^{\mathrm{rc} *}\right)\right], \quad i=1,2, \ldots, n_{j} ; j=1,2, \ldots, n, \\
& \pi_{j}^{\mathrm{df} *}=\pi_{j}^{d / \mathrm{ds}}+\frac{1}{4}\left[\left(\pi_{j}^{\mathrm{mc}}-\pi_{j}^{m / \mathrm{ds}}\right)+\left(\pi_{j}^{d c *}-\pi_{j}^{d / \mathrm{ds}}\right)-2 \sum_{i=1}^{n_{j}}\left(\pi_{i j}^{r / \mathrm{ds}}-\pi_{i j}^{\mathrm{rc} *}\right)\right], \quad j=1,2, \ldots, n, \\
& \pi^{\mathrm{mf} *}=\pi^{m / \mathrm{ds}}+\frac{1}{2}\left[\left(\pi^{\mathrm{mc} *}-\pi^{m / \mathrm{ds}}\right)+\sum_{j=1}^{n}\left(\pi_{j}^{\mathrm{dc} *}-\pi_{j}^{d / \mathrm{ds}}\right)\right] .
\end{aligned}
$$

From the above bargaining process, following results can be realized. First, unlike the centralized decision, the ranges of the contract parameters ensure win-win opportunities for all the channel members. Moreover, the channel is coordinated and maximum channel surplus profit is distributed among the channel members. Second, the manufacturer shares the surplus profit for channel coordination with the $j$ th $(j=1,2, \ldots, n)$ distributor equitably. Third, the $j$ th distributor and its $i$ th $\left(i=1,2, \ldots, n_{j} ; j=1,2, \ldots, n\right)$ retailer share the surplus profit equitably.

3.2. BCB Process. Unlike the previous case, here we approach form the retailers to the manufacturer through the distributors. The sequence of events applying contract mechanisms and bargaining is as follows:

(1) The $j$ th $(j=1,2, \ldots, n)$ distributor and each of its $n_{i j}$ retailers determine the ranges of subsidy on holding cost. The lower limit is the same as the previous case.

(2) The $j$ th distributor $(j=1,2, \ldots, n)$ bargains with each retailer independently for percentage share of retailer's holding cost within its range and settles for a profit distribution. Decentralized profit plus the surplus profit share is the optimal profit of the $i j$ th retailer. After the process, the distributor's immediate profit is the decentralized profit plus cumulative surplus profit shares from all the retailers.

(3) Based on this profit, the jth distributor and the manufacturer identify the range of WPD for win-win profits. The lower limit can be determined by assuming that the distributor accepts the WPD as long as its decentralized profit is reserved and the upper limit is the same as the previous case.

(4) The manufacturer and the $j$ th distributor bargain for profit share. The $j$ th distributor's optimal profit is as follows: decentralized profit + accumulated surplus profit share from its retailers + surplus profit share from the manufacturer. The manufacturer's profit is decentralized profit plus accumulated profits from all the distributors.

The $j$ th distributor's decentralized and centralized profit corresponding to its $i j$ th retailer are, respectively, as

$$
\begin{aligned}
& \pi_{i j}^{\mathrm{dc}}=\frac{Q_{i j}^{\mathrm{rc} *}}{Q_{j}^{\mathrm{dc} *}} \pi_{j}^{\mathrm{dc} *}, \quad i=1,2, \ldots, n_{j} ; j=1,2, \ldots, n, \\
& \pi_{i j}^{d}=\frac{D_{i j}^{r} T_{j}^{d / \mathrm{ds}}}{Q_{j}^{d / \mathrm{ds}}} \pi_{j}^{d / \mathrm{ds}}, \quad i=1,2, \ldots, n_{j} ; j=1,2, \ldots, n .
\end{aligned}
$$

If the $j$ th distributor shares maximum $\overline{\lambda_{i j}}$ percent of holding cost to its $i j$ th retailer, then

$$
{\overline{\lambda_{i j}}}_{b}\left[\frac{h_{i j}^{r} D_{i j}^{r} T^{*}}{2}\right]=\pi_{i j}^{\mathrm{dc}}-\pi_{i j}^{d},
$$

i.e.,

$$
{\overline{\lambda_{i j}}}^{b}=\frac{2\left(\pi_{i j}^{\mathrm{dc}}-\pi_{i j}^{d}\right)}{h_{i j}^{r} D_{i j}^{r} T^{*}}, \quad i=1,2, \ldots, n_{j} ; j=1,2, \ldots, n .
$$

Therefore, any $\lambda_{i j} \in\left(\lambda_{i j},{\overline{\lambda_{i j}}}^{b}\right), \quad\left(i=1,2, \ldots, n_{j} ; j=\right.$ $1,2, \ldots, n)$ ensures that the $\overline{j \text { th }}$ distributor's profit only for $i j$ th retailer and $i j$ th retailer's profit are win-win. Now, within this range, the $j$ th distributor and the $i j$ th retailer bargain for a particular compensation fraction that effectively divides the benefit.

Since any $\lambda_{i j} \in\left(\lambda_{i j}, \overline{\lambda_{i j}}{ }^{b}\right)$ resolves channel conflicts, the $j$ th distributor and the $i j$ th retailer bargain to determine an acceptable $\lambda_{i j} \in\left(\lambda_{i j}, \overline{\lambda_{i j}}\right)$ that will maximize the Nash bargaining product. The Nash bargaining product can be found as

$$
\begin{aligned}
& \max _{\substack{\lambda_{i j} \leq \lambda_{i j} \leq \overrightarrow{\lambda_{i j}} \\
b}}\left[\pi_{i j}^{\mathrm{rc} *}-\pi_{i j}^{r / \mathrm{ds}}+\lambda_{i j}\left(\frac{h_{i j}^{r} D_{i j}^{r} T^{*}}{2}\right)\right] \\
& \quad\left[\pi_{i j}^{\mathrm{dc}}-\pi_{i j}^{d}-\lambda_{i j}\left(\frac{h_{i j}^{r} D_{i j}^{r} T^{*}}{2}\right)\right], \quad i=1,2, \ldots, n_{j} ; j=1,2, \ldots, n .
\end{aligned}
$$

Optimal value of $\lambda_{i j}$ is

$$
\lambda_{i j}^{b}=\frac{\pi_{i j}^{\mathrm{dc}}-\pi_{i j}^{d}+\pi_{i j}^{r / \mathrm{ds}}-\pi_{i j}^{\mathrm{rc} *}}{h_{i j}^{r} D_{i j}^{r} T^{*}}, \quad i=1,2, \ldots, n_{j} ; j=1,2, \ldots, n .
$$

The $j$ th distributor's intermediate profit is 


$$
\pi_{j}^{\mathrm{db}}=\left(w^{d}-w^{m}\right) D_{j}^{d}-\frac{s_{j}^{d}}{T^{*}}-\sum_{i=1}^{n_{j}} \lambda_{i j}^{b}\left[\frac{h_{i j}^{r} D_{i j}^{r} T^{*}}{2}\right], \quad j=1,2, \ldots, n .
$$

As soon as the $j$ th distributor finds optimal cumulative profit gain shares from its $n_{j}$ retailers, it determines the minimum quantity discount that it can accept from the manufacturer. If the manufacturer provides minimum $\rho_{j}^{b}$ discount that ensures the $j$ th distributor's decentralized profit after the first bargaining, then

$$
\underline{\rho_{j}^{b}}=\frac{\pi_{j}^{d / \mathrm{ds}}-\pi_{j}^{\mathrm{db}}}{w^{m} D_{j}^{d}}, \quad j=1,2, \ldots, n .
$$

Any $\rho_{j} \in\left(\rho_{j}^{b}, \overline{\rho_{j}}\right)$ ensures win-win outcomes for the manufacturer and $j$ th distributor. Now, if the $j$ th distributor bargains independently with the manufacturer for a $\rho_{j} \in\left(\rho_{j}^{b}, \overline{\rho_{j}}\right)$ that will maximize their profit, then the Nash bargaining product can be found as

$$
\begin{aligned}
& \max _{\rho_{j}^{b} \leq \rho_{j} \leq \bar{\rho}_{j}}\left[\pi_{j}^{\mathrm{db}}-\pi_{j}^{d / \mathrm{ds}}+\rho_{j} w^{m} D_{j}^{d}\right] \\
& \quad\left[\pi_{j}^{\mathrm{mc}}-\pi_{j}^{m / \mathrm{ds}}-\rho_{j} w^{m} D_{j}^{d}\right], \quad j=1,2, \ldots, n .
\end{aligned}
$$

Optimal value of $\rho_{j}$ is

$$
\rho_{j}^{b}=\frac{\left(\pi_{j}^{\mathrm{mc}}-\pi_{j}^{m / \mathrm{ds}}\right)-\left(\pi_{j}^{\mathrm{db}}-\pi_{j}^{d / \mathrm{ds}}\right)}{2 w^{m} D_{j}^{d}}, \quad j=1,2, \ldots, n .
$$

Therefore, optimal profits of the retailers, the distributors, and the manufacturer are, respectively, as

$$
\begin{aligned}
& \pi_{i j}^{\mathrm{rb} *}=\pi_{i j}^{r / \mathrm{ds}}+\frac{1}{2}\left[\left(\pi_{i j}^{\mathrm{dc}}-\pi_{i j}^{d}\right)-\left(\pi_{i j}^{r / \mathrm{ds}}-\pi_{i j}^{\mathrm{rc} *}\right)\right], \quad i=1,2, \ldots, n_{j} ; j=1,2, \ldots, n, \\
& \pi_{j}^{\mathrm{db} *}=\pi_{j}^{d / \mathrm{ds}}+\frac{1}{4}\left[2\left(\pi_{j}^{\mathrm{mc}}-\pi_{j}^{m / \mathrm{ds}}\right)+\left(\pi_{j}^{\mathrm{dc} *}-\pi_{j}^{d / \mathrm{ds}}\right)-\sum_{i=1}^{n_{j}}\left(\pi_{i j}^{r / \mathrm{ds}}-\pi_{i j}^{\mathrm{rc} *}\right)\right], \quad j=1,2, \ldots, n, \\
& \pi^{\mathrm{mb} *}=\pi^{m / \mathrm{ds}}+\frac{1}{4}\left[2\left(\pi^{\mathrm{mc} *}-\pi^{m / \mathrm{ds}}\right)+\sum_{j=1}^{n}\left(\pi_{j}^{\mathrm{dc} *}-\pi_{j}^{d / \mathrm{ds}}\right)-\sum_{j=1}^{n} \sum_{i=1}^{n_{j}}\left(\pi_{i j}^{r / \mathrm{ds}}-\pi_{i j}^{\mathrm{rc} *}\right)\right] .
\end{aligned}
$$

Note that the $j$ th distributor's average profit in centralized decision is higher when compared with the profit in decentralized decision, i.e., $\quad \pi_{j}^{\mathrm{dc} *}>\pi_{j}^{d / \mathrm{ds}}$, i.e., $\pi_{j}^{\mathrm{dc} *}-\pi_{j}^{d / \mathrm{ds}}>0 j=1,2, \ldots, n$. Then, from equation (38), it follows that $\rho_{j}^{f}<0$, since $w^{m} D_{j}^{d}>0$. Similarly, from equation (58), it follows that $\rho_{j}^{b}<0$, because $\pi_{j}^{d / \mathrm{ds}}<\pi_{j}^{\mathrm{db}}$. However, in reality, discount on wholesale price cannot be negative. So, the lower limit of quantity discount is zero. Thus, we have the following proposition.

Proposition 2. In both contract-bargaining processes, without receiving any quantity discount, the distributors can coordinate the channel.

3.3. Comparison of Two Contract-Bargaining Processes. From the above two bargaining procedures, two lower limits of WPD and two upper limits of percentage share on holding cost are identified. Note from equation (58) and equation (38) that

$$
\underline{\rho_{j}^{b}}-\underline{\rho_{j}^{f}}=\frac{\pi_{j}^{\mathrm{dc} *}-\pi_{j}^{\mathrm{db}}}{w^{m} D_{j}^{d}}, \quad j=1,2, \ldots, n .
$$

However, $\pi_{j}^{\mathrm{dc} *}>\pi_{j}^{\mathrm{db}}$. Thus, $\rho_{j}^{b}-\rho_{j}^{f}>0$, since $w^{m} D_{j}^{d}>0$, i.e., $\rho_{j}^{b}>\rho_{j}^{f}$. Thus, minimum $\overline{\mathrm{W}} \mathrm{PD}$ demanded by the $j$ th $(j=\overline{1,2}, \ldots, n)$ distributor in backward process is higher when compared with minimum WPD of forward process. Similarly, ${\overline{\lambda_{i j}}}^{b}-{\overline{\lambda_{i j}}}^{f}<0$; that is, the minimum compensation provided by the $j$ th $(j=1,2, \ldots, n)$ distributor to its $i j$ th $\left(i=1,2, \ldots, n_{j} ; j=1,2, \ldots, n\right)$ retailer in forward process is higher than that of backward. So, we have the following proposition.

Proposition 3. (i) $\rho_{j}^{f}<\rho_{j}^{b}, j=1,2, \ldots, n$ and (ii) ${\overline{\lambda_{i j}}}^{f}>$ ${\overline{\lambda_{i j}}}^{b}, i=1,2, \ldots, n_{j} ; \overline{j=} 1, \overline{2, \ldots, n}$

Moreover,

$$
\begin{aligned}
& \pi_{i j}^{\mathrm{rf} *}-\pi_{i j}^{\mathrm{rb} *}=\frac{1}{2}\left[\pi_{i j}^{\mathrm{df}}-\pi_{i j}^{\mathrm{dc}}\right]=\frac{Q_{i j}^{\mathrm{rc} *}}{2 Q_{j}^{\mathrm{dc} *}}\left[\pi_{j}^{\mathrm{df}}-\pi_{j}^{\mathrm{dc} *}\right]>0, \\
& \pi_{j}^{\mathrm{db} *}-\pi_{j}^{\mathrm{df} *}=\frac{1}{4}\left[\left(\pi_{j}^{m}-\pi_{j}^{d / \mathrm{ds}}\right)+\sum_{i=1}^{n_{j}}\left(\pi_{i j}^{r / \mathrm{ds}}-\pi_{i j}^{\mathrm{rc} *}\right)\right]>0, \\
& \pi^{\mathrm{mf} *}-\pi^{\mathrm{mb} *}=\frac{1}{4}\left[\sum_{j=1}^{n}\left(\pi_{j}^{\mathrm{dc} *}-\pi_{j}^{d / \mathrm{ds}}\right)+\sum_{j=1}^{n} \sum_{i=1}^{n_{j}}\left(\pi_{i j}^{r / \mathrm{ds}}-\pi_{i j}^{\mathrm{rc} *}\right)\right]>0 .
\end{aligned}
$$

Thus, we have the following proposition.

Proposition 4. The manufacturer and the retailers want to promote forward bargaining process, but the distributors want the other. 
The manufacturer and the distributors divide the surplus profit, which is generated due to the adaptation of centralized decisions through symmetric Nash bargaining product. In forward bargaining process for minimum WPD, a distributor's profit is equal to its decentralized profit and the manufacturer's profit is maximum. On the other hand, in backward bargaining process, a distributor bargains with the manufacturer after providing holding cost compensation to its retailers. Obviously, the demand for WPD amount is higher in the later, i.e., $\rho_{j}^{f}<\rho_{j}^{b}$. Thus, the bargaining space between manufacturer and the distributors is wider in backward bargaining when compared with the forward bargaining. Since the surplus profit is divided equitably between the manufacturer and a distributor, the distributor gets more opportunity to gain additional profit in forward bargaining. However, the manufacture and the retailers will be wanted to promote $\mathrm{BCB}$ process as they get more opportunity in this process.

\section{Numerical Results}

Assume that a supply chain network with five retailers $R_{11}$, $R_{21}, R_{12}, R_{22}$, and $R_{32}$, two distributors $D_{1}$ and $D_{2}$, and a manufacturer $M$, where the distributor $D_{1}$ supplies the product to $R_{11}$ and $R_{21}$ and the distributor $D_{2}$ supplies the product to the other three retailers. Parameter values of the manufacturer are $s^{m}=12000, h^{m}=4.5, c^{m}=130$, and $w^{m}=165$, and other parameters are $w^{d}=200 p=250$. Parameter values of the retailers and the distributors are shown in Table 2. Based on the solution procedure of Appendix $\mathrm{C}$ and the parameter values, the computational results are presented in Tables 3-6.

From Table 3, note that total profit of the channel is maximum in centralized decision making, whereas it is least in decentralized decision making. Optimal channel profit is increased by $14.23 \%$ in centralized decision. The manufacturer's profit and all the distributors' total profit are increased by $39.05 \%$ and $26.91 \%$, but the sum of the retailers' total profit is decreased by $5.47 \%$ when compared with decentralized decisions. Thus, the centralized decisions are not acceptable to the retailers unless they get some incentives from the distributors.

When the contract-bargaining processes are used, the optimal profits are 182643, the same as the centralized channel. Thus, by applying any one of these two processes, it is possible to resolve the channel conflict. Moreover, all channel members' profits are higher when compared with decentralized profits.

Both contract-bargaining processes create win-win opportunities for all the channel members, and the ranges of contract parameters are different in two processes (see Tables 5 and 6).

For example, the ranges of percentage subsidy on holding cost for the $R_{22}$ in backward and forward processes are $(0.4159,1.0445)$ and $(0.4159,1.175)$. As indicated, the lower limits are the same. Also note that when the contractbargaining processes are used, the optimal profits are 182643, the same as the centralized channel. Thus, by
TABLE 2: Input parameters of retailers $(R)$ and distributors $(D)$.

\begin{tabular}{lccc}
\hline Retailer & $s_{i j}^{r}$ (\$/order) & $h_{i j}^{r}(\$ /$ unit/year) & $D_{i j}^{r}$ (items/year) \\
\hline$R_{11}$ & 550 & 7 & 300 \\
$R_{21}$ & 580 & 7.5 & 375 \\
$R_{12}$ & 550 & 6.75 & 305 \\
$R_{22}$ & 600 & 7.5 & 400 \\
$R_{32}$ & 575 & 7.25 & 325 \\
\hline Distributor & $s_{j}^{d}(\$ /$ order $)$ & $h_{j}^{d}(\$ /$ unit/year $)$ \\
\hline$D_{1}$ & 2200 & 5 \\
$D_{2}$ & 2500 & 5 & \\
\hline
\end{tabular}

TABLE 3: Computational results for decentralized, semicentralized, and centralized policies.

\begin{tabular}{lccc}
\hline Decision variables & Decentralized & Semicentralized & Centralized \\
\hline$T$ & - & 0.680582 & 1.78117 \\
$\alpha$ & - & 2 & - \\
$\beta$ & - & 1 & - \\
$\begin{array}{l}\text { Retailers' total } \\
\text { profit }\end{array}$ & 76876 & 76860 & 72669 \\
$\begin{array}{l}\text { Distributors' total } \\
\text { profit }\end{array}$ & 44942 & 53321 & 57036 \\
$\begin{array}{l}\text { Manufacturer's } \\
\text { profit }\end{array}$ & 38070 & 50859 & 52938 \\
Channel profit & 159888 & 181040 & 182643 \\
\hline
\end{tabular}

applying any one of these two processes, it is possible to resolve the channel conflict. Moreover, all channel members' profits are higher when compared with decentralized profits.

From Tables 5 and 6 , one may note that the percentage increments in profits of the distributors in backward process are higher. The retailers' and the manufacturer's percentage increments in profits are higher in FCB process. Thus, the distributors prefer backward process, whereas the retailers and the manufacturer prefer the forward. This is quite obvious because the bargaining space in backward process over which the manufacturer and the distributors bargain is wider compared to the forward process. The reverse trend may be observed for percentage subsidy on the retailers' holding cost. Also, the characteristics remain the same for the change in input parameters values (see Figure 2).

The first three subfigures in Figure 2 present the effects of the key parameters (demand, holding cost, and setup cost) of the retailers on the solution space on the percentage share on holding cost in $\mathrm{BCB}$ and $\mathrm{FCB}$ processes, while the remaining three subfigures in Figure 2 show the effects of the distributers' demand, holding cost, and setup cost on the solution space on WPD in the two bargaining processes. Figure 2(a) depicts that although the ijth retailer's demand has little effect on the limits of percentage share on holding costs, the solution spaces decrease if demand increases for both the BCB and FCB processes. Figure 2(b) shows that the limits of percentage share on holding costs are highly sensitive to the retailer's holding cost. The upper limits of percentage share on holding costs in both the $\mathrm{BCB}$ and $\mathrm{FCB}$ processes are decreasing with increasing holding costs of the $i j$ th retailer. On the other hand, the lower limit of percentage share on holding cost is increasing with increasing holding 
TABLE 4: Computational result for individuals in decentralized, semicentralized, and centralized policies.

\begin{tabular}{|c|c|c|c|c|c|c|c|c|c|}
\hline \multirow{2}{*}{ Members } & \multicolumn{3}{|c|}{ Decentralized } & \multicolumn{3}{|c|}{ Semicentralized } & \multicolumn{3}{|c|}{ Centralized } \\
\hline & Time & Q & Profit & Time & $Q$ & Profit & Time & $Q$ & Profit \\
\hline$R_{11}$ & 0.7237 & 217 & 13480 & 0.6806 & 204 & 13477 & 1.7812 & 534 & 12821 \\
\hline$R_{21}$ & 0.6422 & 240 & 16944 & 0.6806 & 255 & 16941 & 1.7812 & 668 & 15920 \\
\hline$R_{12}$ & 0.7309 & 223 & 13745 & 0.6806 & 208 & 13741 & 1.7812 & 543 & 13108 \\
\hline$R_{22}$ & 0.6324 & 253 & 18103 & 0.6806 & 272 & 18098 & 1.7812 & 712 & 16991 \\
\hline$R_{32}$ & 0.6986 & 227 & 14604 & 0.6806 & 221 & 14603 & 1.7812 & 579 & 13828 \\
\hline$D_{1}$ & 1.1418 & 771 & 17481 & 1.3612 & 918 & 20860 & 1.7812 & 1202 & 22390 \\
\hline$D_{2}$ & 0.9853 & 1015 & 27461 & 1.3612 & 1402 & 32461 & 1.7812 & 1834 & 34646 . \\
\hline$M$ & 1.7686 & 3016 & 38070 & 1.3612 & 2320 & 50859 & 1.7812 & 3036 & 52938. \\
\hline
\end{tabular}

TABLE 5: Computational result for backward contract-bargaining process.

\begin{tabular}{|c|c|c|c|c|c|c|c|c|}
\hline Members & $\underline{\lambda_{i j}}$ & $\lambda_{i j}^{b}$ & ${\overline{\lambda_{i j}}}^{b}$ & $\underline{\rho_{j}^{b}}$ & $\rho_{j}^{b}$ & $\overline{\rho_{j}}$ & Profit & $\%$ increase in profit \\
\hline$R_{11}$ & 0.3524 & 0.7594 & 1.1664 & - & - & - & 14241 & 5.64 \\
\hline$R_{21}$ & 0.4089 & 0.7488 & 1.0886 & - & - & - & 17795 & 5.02 \\
\hline$R_{12}$ & 0.3476 & 0.7541 & 1.1605 & - & - & - & 14491 & 5.42 \\
\hline$R_{22}$ & 0.4159 & 0.7302 & 1.0445 & - & - & - & 18942 & 4.63 \\
\hline$R_{32}$ & 0.3694 & 0.7249 & 1.0805 & - & - & - & 15350 & 5.11 \\
\hline$D_{1}$ & - & - & - & 0 & 0.0192 & 0.0264 & 21231 & 21.45 \\
\hline$D_{2}$ & - & - & - & 0 & 0.0196 & 0.0264 & 33117 & 20.60 \\
\hline$M$ & - & - & - & - & - & - & 47540 & 24.88 \\
\hline
\end{tabular}

TABLE 6: Computational result for forward contract-bargaining process.

\begin{tabular}{|c|c|c|c|c|c|c|c|c|}
\hline Members & $\lambda_{i j}$ & $\lambda_{i j}^{b}$ & ${\overline{\lambda_{i j}}}^{f}$ & $\rho_{j}^{f}$ & $\rho_{j}^{f}$ & $\overline{\rho_{j}}$ & Profit & $\%$ increase in profit \\
\hline$R_{11}$ & 0.3524 & 0.8175 & 1.2826 & - & - & - & 14350 & 6.45 \\
\hline$R_{21}$ & 0.4089 & 0.8030 & 1.1971 & - & - & - & 17931 & 5.83 \\
\hline$R_{12}$ & 0.3476 & 0.8266 & 1.3056 & - & - & - & 14623 & 6.39 \\
\hline$R_{22}$ & 0.4159 & 0.7955 & 1.1750 & - & - & - & 19116 & 5.60 \\
\hline$R_{32}$ & 0.3694 & 0.7925 & 1.2155 & - & - & - & 15492 & 6.08 \\
\hline$D_{1}$ & - & - & - & 0 & 0.0044 & 0.0264 & 19338 & 10.62 \\
\hline$D_{2}$ & - & - & - & 0 & 0.0053 & 0.0264 & 30241 & 10.12 \\
\hline$M^{2}$ & - & - & - & - & - & - & 51703 & 35.81 \\
\hline
\end{tabular}

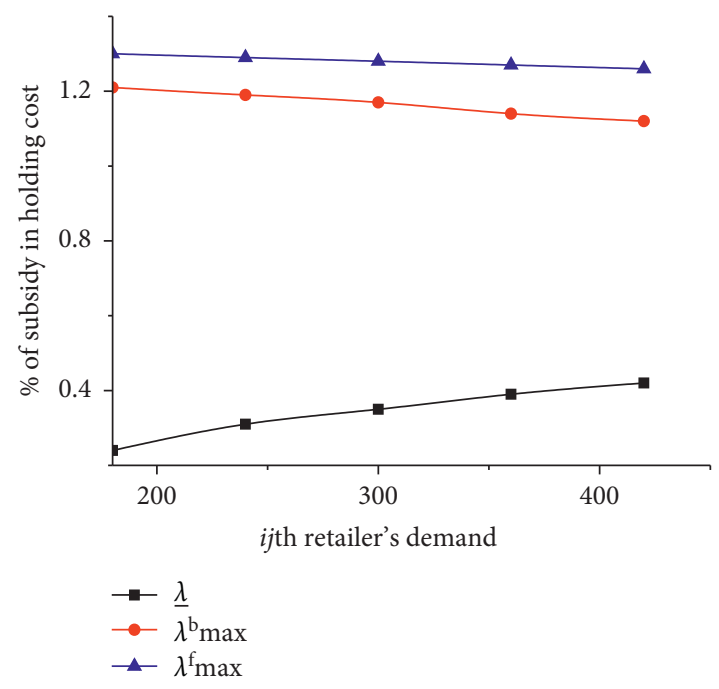

(a)

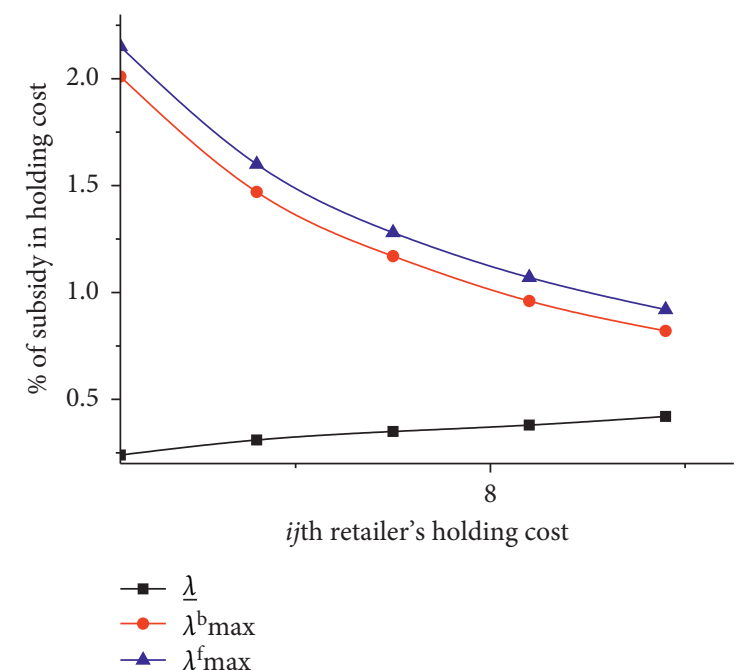

(b)

Figure 2: Continued. 


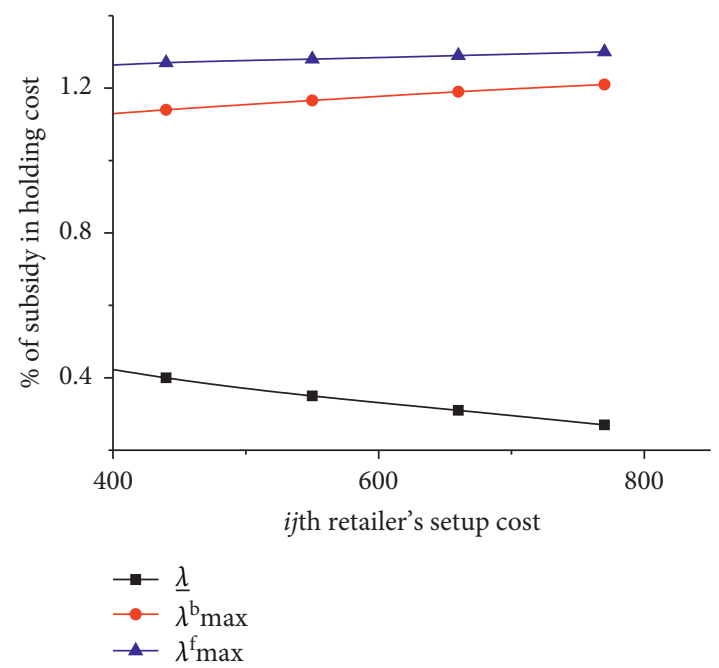

(c)

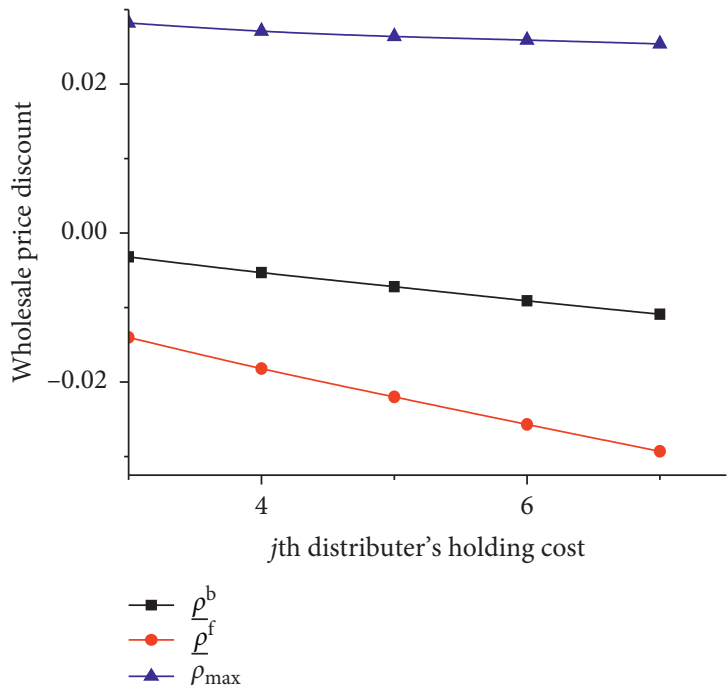

(e)

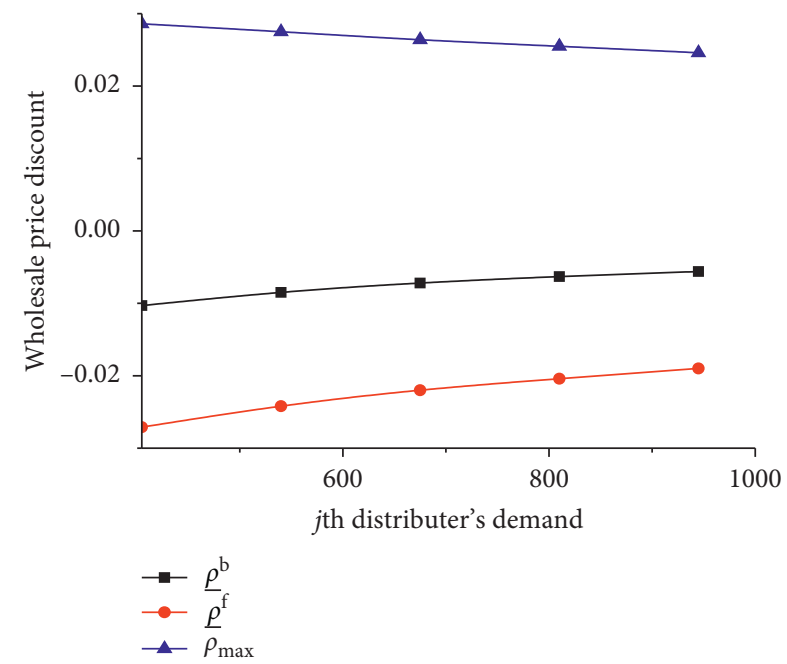

(d)

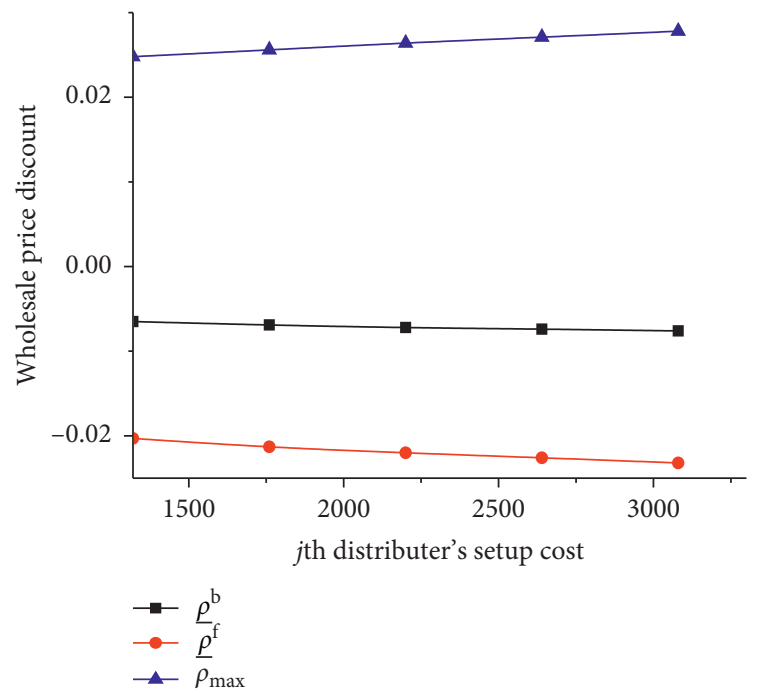

(f)

FIgURE 2: Variations in decision variables with respect to change in input parameter values.

cost of the $i j$ th retailer. In this way, the solution space decreases when holding cost of the $i j$ th retailer increases. Figure 2(c) displays that the limits of percentage share on holding costs are less sensitive on the $i j$ th retailer's setup cost. Solution spaces in both the bargaining processes increase if the $i j$ th retailer's setup cost increases. Figure 2(d) portrays that changes in the jth distributer's demand have a low impact on the limits of WPD and the solution spaces in both the BCB and FCB processes are decreasing with the increasing demand of the $j$ th distributer. Figures $2(e)$ and 2(f) show that the distributer's holding cost and setup cost have a similar effect on the limits of WPD and the solution spaces in both the $\mathrm{BCB}$ and FCB processes increase with increasing holding cost and setup cost of the $j$ th distributer.

The upper limits of percentage subsidy on holding cost in both the processes are higher than one. That is, a distributor may provide more than its holding cost as subsidy to a retailer, and still its profit is win-win. It occurs when the surplus profit that a distributor receives due to channel coordination is higher than the holding cost of a retailer. The lower limits of WPD in the contract-bargaining processes are zero. It simply demonstrates that, if the distributors do not get discounts from the manufacturer, then also they have the power to coordinate the channel by providing subsidies on holding costs of the retailers'. In that case, they can also enjoy win-win profits until the upper limits are zero.

Some more sensitivity analyses of the optimal average bargaining profit functions are performed and are presented in Figure 3. Figure 3(a) shows that all the channel members' profits increase (or decrease) significantly with the increasing (or decreasing) demand. Profit of the ijth retailer, the $j$ th distributer, and the manufacturer increases, $41.3 \%$, $44.7 \%$, and $43.3 \%$, respectively, when demand increases 40 percent. Figure 3 (b) depicts that the manufacturer's profit is 


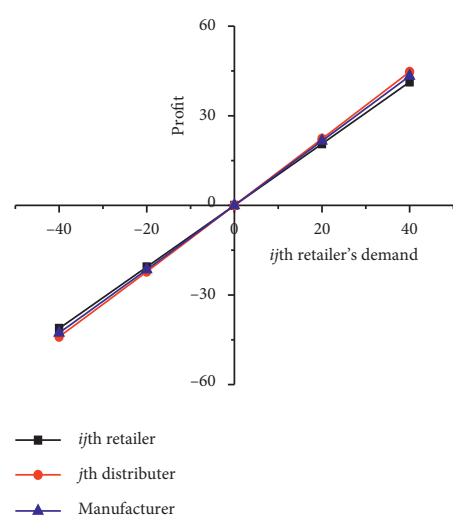

(a)

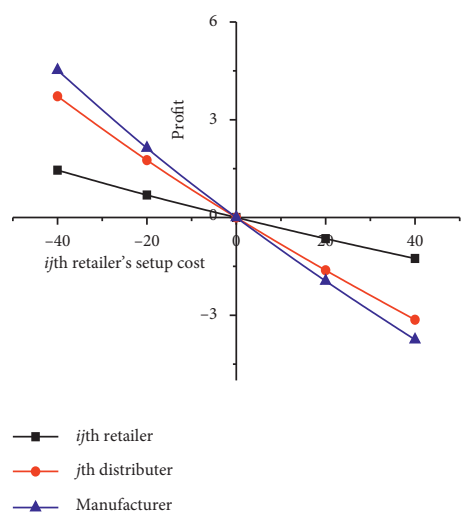

(b)

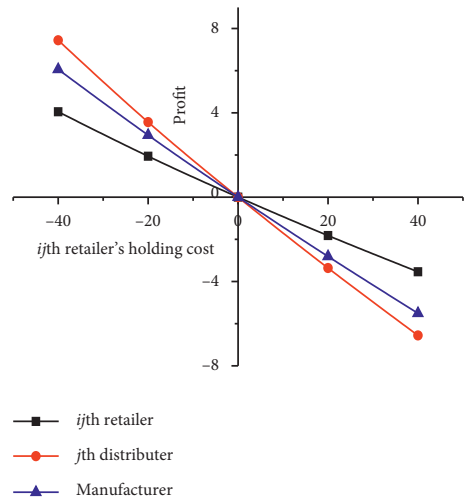

(c)

FIGURE 3: Fluctuations in bargaining profits with respect to the retailers input parameter values.

more sensitive to the retailer's setup cost. Forty percent increase in the retailer's setup cost will decrease $3.75 \%$, $3.14 \%$, and $1.26 \%$ of profits of the manufacturer, the $j$ th distributer, and the retailer, respectively. Figure 3(c) shows that the distributers' profit is more sensitive to the retailers holding cost. Forty percent increase in the retailers holding cost will decrease $6.56 \%, 5.51 \%$, and $3.54 \%$ of profits of the $j$ th distributor, manufacturer, and the retailer, respectively. Figure 3 indicates that the bargaining profits are highly sensitive for the change in demand at the retailers' end and low sensitivity may be observed for the error in the estimation of setup costs of the channel members and holding costs of the retailers. The same characteristics of the optimal average bargaining profit functions may be observed for the change in the parameter values of the distributors and the manufacturer.

In real-world business scenarios, it is important to maximize the outputs of a supply chain. We have planned and used a hybrid contract for coordination as it is not possible to coordinate this model through a single coordination contract mechanism. Our proposed hybrid contract can fully coordinate the tree-like supply chain. This means the proposed hybrid contract can enrich the entire profit of the supply chain at its best. Moreover, two bargaining processes are implemented to share the additional profits among the channel members. This ensures a win-win outcome for all the channel members of the supply chain.

\section{Summary and Concluding Remarks}

The paper analyzes about the coordination and surplus profit division in a conventional distribution channel. Using two nested contract-bargaining processes, attempts are made to find cooperative decision which effectively resolve channel conflict and find win-win opportunities for all the channel members. The contract-bargaining processes are very close to business practice because an upstream channel member interacts with each of its downstream channel members independently in one-to-one basis. It is quite obvious that an upstream channel member will provide how much benefit to a downstream channel member that depends on how much it receives from that member. Numerical example suggests that an upstream channel member has different reservations for its corresponding downstream channel members. Earlier studies in this direction have considered an integrated approach through synchronized order quantity or replenishment cycle. As a result, some channel members are benefited from the decision and some are not. Apart from few, earlier studies on two-echelon supply chain coordination have considered a particular benefit split rather than assuming that a channel member may have the right to say something about the benefit share. In this direction, the present paper also extends the literature by assuming that the channel members bargain to divide the channel surplus. However, the centralized, semicentralized, and decentralized decisions are derived in 
closed forms and some interesting results are found for a distribution channel; those are summarized below.

Firstly, although centralized decision provides best channel performance, the manufacturer and the distributors are benefited, but the retailers are not. The centralized decision is acceptable to the retailers when they get some incentives from the upstream channel members. Secondly, as incentives, the WPD and subsidy on holding cost of the retailer cut out channel conflict and find win-win profits for the channel members. Thirdly, using Nash bargaining product, it is always possible to find particular profit shares for all the channel members. Fourthly, two contract-bargaining processes are designed in such a way that an upstream channel member always has the opportunity to account different reservations for its different downstream members. Fifthly, the ranges of contract parameters, which provide win-win opportunities, are different in two contractbargaining processes, i.e., the monetary space over which the channel members' bargain differs, so their profit share as well. As a result, the distributors prefer the backward process, whereas the manufacturer and the retailers prefer the forward. Sixthly, in both contract-bargaining processes, the manufacturer may not provide WPD. That is, without receiving any discount from the manufacturer, the distributors have the power to coordinate the channel by subsidizing its corresponding retailers' holding costs. By doing so, it still can find some profit share because the upper limit of percentage subsidy on holding cost is positive.

Although the model is developed by considering uniform demand, models may be formulated by considering price dependent and stock/price dependent or stochastic demand. In our view, the main results of the paper will not differ for such demand patterns. An important limitation of the paper is the assumption of common cycle approach. A model may be developed by relaxing it. In such case, the model will be more general though computation will be more complex. Instead of considering WPD and subsidy on holding cost, some other coordination contracts may be used in the contract-bargaining processes. The surplus profit is distributed among the channel members equitably in oneto-one basis. The model may be analyzed by considering asymmetric Nash bargaining product.

\section{Appendix}

\section{A. The Optimal Decision of the $j$ th Distributor in the First Cycle}

The average profit function of the $j$ th $(j=1,2, \ldots, n)$ distributor in the first order cycle is

$$
\begin{aligned}
\pi_{j}^{d 1}= & \left(w^{d}-w^{m}\right) D_{j}^{d}-\frac{s_{j}^{d}}{T_{j}^{d 1}}-h_{j}^{d} \sum_{i=1}^{n_{j}} Q_{i j}^{r / \mathrm{ds}} \\
& -\frac{h_{j}^{d}\left[T_{j}^{d 1} D_{j}^{d}-\sum_{i=1}^{n_{j}} Q_{i j}^{r / \mathrm{d} s}\right]}{2}-\frac{w^{m} \sum_{i=1}^{n_{j}} Q_{i j}^{r / \mathrm{d} s}}{T_{j}^{d 1}} .
\end{aligned}
$$

The second term is purchasing cost of safety stock anticipating the orders from retailers at the same time. The third term above is the holding costs per unit time for a distributor if the distributor is to have zero stock outs. Fourth term is the holding costs for the general stock, $T_{j}^{d 1} D_{j}^{d}-\sum_{i=1}^{n_{j}} Q_{i j}^{r / d s}$ because at the beginning of order cycle, products at distributors will be immediately used to satisfy the first order from retailers. Differentiating $\pi_{j}^{d 1}$ with respect to $T_{j}^{d 1}$ and equating to zero, we get

$$
T_{j}^{d 1}=\sqrt{\frac{2\left[s_{j}^{d}+w^{m} \sum_{i=1}^{n_{j}} Q_{i j}^{r / \mathrm{ds}}\right]}{h_{j}^{d} D_{j}^{d}}}, \quad j=1,2, \ldots, n
$$

Thus, the order quantity of the $j$ th distributor in the initial replenishment will be

$$
Q_{j}^{d 1}=\sum_{i=1}^{n_{j}} Q_{i j}^{r / \mathrm{d} s}+\sqrt{\frac{2\left[s_{j}^{d}+w^{m} \sum_{i=1}^{n_{j}} Q_{i j}^{r / \mathrm{ds}}\right] D_{j}^{d}}{h_{j}^{d}}}, \quad j-1,2, \ldots, n .
$$

Since $\quad d^{2} \pi_{j}^{d 1} / d T_{j}^{d 12}=-\left[2\left(s_{j}^{d}+w^{m} \sum_{i=1}^{n_{j}} Q_{i j}^{r / d s}\right)\right]\left[\left(T_{j}^{d 1}\right)^{3}\right]$ $<0$, therefore, (A.1) is a concave function in $T_{j}^{d 1}$, and the optimal solution of (A.2) is a global optimum.

\section{B. The Optimal Decision of the Manufacturer in the First Cycle}

The production lot of the manufacturer is

$$
Q^{m 1}=\sum_{j=1}^{n} Q_{j}^{d / d s}+T^{m} D^{m}
$$

Therefore, the average profit function of the manufacturer is

$$
\begin{aligned}
\pi^{m 1}= & \left(w^{m}-c^{m}\right) D^{m}-\frac{\sum_{j=1}^{n} Q_{j}^{d / \mathrm{ds}} c^{m}}{T^{m 1}}-\frac{s^{m}}{T^{m 1}} \\
& -h^{m} \sum_{j=1}^{n} Q_{j}^{d / \mathrm{d} s}-\frac{h^{m}\left[T^{m 1} D^{m}-\sum_{j=1}^{n} Q_{j}^{d 1}\right]}{2} .
\end{aligned}
$$

Differentiating $\pi^{m 1}$ with respect to $T^{m 1}$ and equating to zero, the optimal cycle length of the manufacturer for first cycle is found as

$$
T^{m 1}=\sqrt{\frac{2\left[s^{m}+c^{m} \sum_{j=1}^{n} Q_{j}^{d / d s}\right]}{h^{m} D^{m}}}
$$

The optimal production size of the manufacturer for the first cycle is

$$
Q^{m 1}=\sum_{j=1}^{n} Q_{j}^{d / \mathrm{d} s}+\sqrt{\frac{2\left[s^{m}+c^{m} \sum_{j=1}^{n} Q_{j}^{d / \mathrm{d} s}\right] D^{m}}{h^{m}}}
$$




$$
\frac{d^{2} \pi^{m 1}}{d T^{m 12}}=-\frac{2\left(s^{m}+c^{m} Q^{m 1}\right)}{\left(T^{m 1}\right)^{3}}<0 .
$$

Therefore, (B2) is a concave function of $T^{m 1}$.

\section{Solution Procedure to Find the Optimal Solutions}

Solution procedure to find the optimal solution.

Input parameter values.

Procedure 1. //Decentralized decision//

$$
\begin{aligned}
& \mathrm{TPD}=0, D_{m}=0 \\
& \text { for }(j=1 \text { to } n) \\
& \mathrm{TPR}_{j}=0, D_{j}^{d}=0 \\
& \quad \text { for }\left(i=1 \text { to } n_{j}\right) \\
& \quad \text { calculate } T_{i j}^{r / \mathrm{ds}}, Q_{i j}^{r / \mathrm{ds}} \text { and } \pi_{i j}^{r / \mathrm{ds}} \text { using equations (2), }
\end{aligned}
$$

(4) and (5)

$$
\begin{aligned}
& \mathrm{TPR}_{j}=\mathrm{TPR}_{j}+\pi_{i j}^{r / d s} \\
& D_{j}^{d}=D_{j}^{d}+Q_{i j}^{r / \mathrm{ds}} / T_{i j}^{r / \mathrm{ds}}
\end{aligned}
$$

write output $T_{i j}^{r / \mathrm{ds}}, Q_{i j}^{r / \mathrm{ds}}, \pi_{i j}^{r / \mathrm{ds}}$ and $\mathrm{TPR}_{j}$

calculate $T_{j}^{d / \mathrm{ds}}, Q_{j}^{d / \mathrm{ds}}$ and $\pi_{j}^{d / \mathrm{ds}}$ using equations (9), (11), and (12)

$$
\begin{aligned}
& \mathrm{TPD}=\mathrm{TPD}+\pi_{j}^{d / \mathrm{ds}} \\
& D^{m}=D^{m}+Q_{j}^{d / \mathrm{ds}} / T_{j}^{d / \mathrm{ds}}
\end{aligned}
$$

write output $T_{j}^{d / \mathrm{ds}}, Q_{j}^{d / \mathrm{ds}}, \pi_{j}^{(d / \mathrm{ds})}$ and TP D

calculate $T^{m / d s}, Q^{m / d s}$ and $\pi^{(m / d s)}$ using equations (16), (18), and (19)

write output $T^{m / \mathrm{ds}}, Q^{m / \mathrm{ds}}, \pi^{m / \mathrm{ds}}$

\section{Procedure 2. //Semicentralized decision//}

calculate $T_{i j}^{s}$, $Q_{i j}^{\mathrm{rs}}$ and $\pi_{i j}^{\mathrm{rs}}$ using equations (21), (22), and (20)

$$
\begin{aligned}
& \alpha=1, A=0 \\
& \text { repeat } \\
& \quad \text { calculate } \pi^{\mathrm{ds}} \text { using (21) } \\
& \begin{array}{l}
A=\pi^{\mathrm{ds}} \\
\alpha=\alpha+1
\end{array}
\end{aligned}
$$

until $\left(\pi^{\mathrm{ds}}>A\right)$

write output $\alpha, A$ as distributors' cost

$\beta=1, B=0$

repeat

$$
\begin{aligned}
& \text { calculate } \pi^{\mathrm{ms}} \\
& B=\pi^{\mathrm{ms}} \\
& \beta=\beta+1 \\
& \text { until }\left(\pi^{\mathrm{ms}}>B\right)
\end{aligned}
$$

write output $\beta, B$ as manufacturer's cost
Procedure 3. //Centralized decision//

calculate $T^{*}, Q_{i j}^{\mathrm{rc} *}, Q_{j}^{\mathrm{dc} *}, Q^{\mathrm{mc} *}, \pi_{i j}^{\mathrm{rc} *}, \pi_{j}^{\mathrm{dc} *}$ and $\pi^{\mathrm{mc} *}$ using equations (26) to (33)

Procedure 4. //Minimum and maximum contract limits for retailers and manufacturer//

$$
\begin{aligned}
& \text { for }(j=1 \text { to } n) \\
& \quad \text { for }\left(i=1 \text { to } n_{j}\right) \\
& \quad \text { calculate } \lambda_{i j} \text { using (43) }
\end{aligned}
$$

calculate $\pi_{j}^{\mathrm{mc*}}, \pi_{j}^{m *}$ and $\overline{\rho_{j}}$ using equations (34), (35), and (37)

Procedure 5. //FCB process//

for $(j=1$ to $n)$

calculate $\rho_{j}^{f}, \rho_{j}^{f}$ and $\pi_{j}^{\mathrm{df}}$ using (38), (40), and (41)
for $(j=1$ to $n)$

$$
\text { for }\left(i=1 \text { to } n_{j}\right)
$$

calculate $\pi_{i j}^{\mathrm{df}}, \overline{\lambda_{i j}^{f}}$ and $\lambda_{i j}^{f}$ using (44), (45), and (47)

for $(j=1$ to $n)$

for $\left(i=1\right.$ to $\left.n_{j}\right)$

calculate $\pi_{i j}^{\mathrm{rf} *}$ using (48)

calculate $\pi_{j}^{\mathrm{df} *}$ using (49)

calculate $\pi^{\mathrm{mf*}}$ using (50)

write output $\lambda_{i j}^{f}, \pi_{i j}^{r f *}, \pi_{j}^{\mathrm{df} *}, \pi^{\mathrm{mf} *}$

Procedure 6. //BCB process//

$$
\text { for }(j=1 \text { to } n)
$$

for $\left(i=1\right.$ to $\left.n_{j}\right)$

$$
\text { calculate } \pi_{i j}^{\mathrm{dc}}, \pi_{i j}^{d / \mathrm{ds}} \text { and } \overline{\lambda_{i j}^{b}} \text { using (51), (52), and }
$$

determine $\lambda_{i j}^{b}$ using (56)

determine $\rho_{j}^{b}$ and $\rho_{j}^{b}$ using (58) and (60)

for $(j=1$ to $n)$

for $\left(i=1\right.$ to $\left.n_{j}\right)$

calculate $\pi_{i j}^{\mathrm{rb} *}$ using (61)

calculate $\pi_{j}^{\mathrm{db} *}$ using (62)

calculate $\pi^{\mathrm{mb} *}$ using (63)

write output $\lambda_{i j}^{b}, \pi_{i j}^{\mathrm{rb} *}, \pi_{j}^{\mathrm{db} *}, \pi^{\mathrm{mb} *}$

\section{List of Abbreviations}

FCB: forward contract-bargaining

BCB: backward contract-bargaining

PCHC: percentage of compensation on holding cost

WPD: wholesale price discount. 


\section{Data Availability}

The data used to support the findings of this study are included within the article.

\section{Conflicts of Interest}

There are no conflicts of interest in the manuscript.

\section{References}

[1] K. Salas Navarro, J. A. Chedid, J. Acevedo Chedid et al., "A collaborative EPQ inventory model for a three-echelon supply chain with multiple products considering the effect of marketing effort on demand," Journal of Industrial \& Management Optimization, vol. 16, no. 4, pp. 1613-1633, 2020.

[2] S. Panda, N. M. Modak, and L. E. Cárdenas-Barrón, "Coordination and benefit sharing in a three-echelon distribution channel with deteriorating product," Computers \& Industrial Engineering, vol. 113, pp. 630-645, 2017.

[3] N. M. Modak, S. Sinha, S. Panda, and N. Kazemi, "Analyzing a socially responsible closed-loop distribution channel with recycling facility," SN Applied Sciences, vol. 1, no. 10, pp. 1-14, 2019.

[4] G. P. Cachon, "Supply chain coordination with contracts," in Handbooks in Operations Research and Management Science, S. Graves and T. de Kok, Eds., Elsevier, Amsterdam, Netherlands, 2003.

[5] M. Y. Jaber, I. H. Osman, and A. L. Guiffrida, "Coordinating a three-level supply chain with price discounts, price dependent demand, and profit sharing," International Journal of Integrated Supply Management, vol. 2, no. 1/2, pp. 28-48, 2006.

[6] B. Van Der Rhee, J. A. A. Van Der Veen, V. Venugopal, and V. R. Nalla, "A new revenue sharing mechanism for coordinating multi-echelon supply chains," Operations Research Letters, vol. 38, no. 4, pp. 296-301, 2010.

[7] N. M. Modak and P. Kelle, "Managing a dual-channel supply chain under price and delivery-time dependent stochastic demand," European Journal of Operational Research, vol. 272, no. 1, pp. 147-161, 2019.

[8] R. Ganeshan, "Managing supply chain inventories: a multiple retailer, one warehouse, multiple supplier model," International Journal of Production Economics, vol. 59, no. 1-3, pp. 341-354, 1999.

[9] M. Khouja, "Optimizing inventory decisions in a multi-stage multi-customer supply chain," Transportation Research Part E: Logistics and Transportation Review, vol. 39, no. 3, pp. 193-208, 2003.

[10] M. Ben-Daya and A. Al-Nassar, "An integrated inventory production system in a three-layer supply chain," Production Planning \& Control, vol. 19, no. 2, pp. 97-104, 2008.

[11] M. Khouja, "Synchronization in supply chains: implications for design and management," Journal of the Operational Research Society, vol. 54, no. 9, pp. 984-994, 2003.

[12] L. E. Cárdenas-Barrón, "Optimizing inventory decisions in a multi-stage multi-customer supply chain: a note," Transportation Research Part E: Logistics and Transportation Review, vol. 43, no. 5, pp. 647-654, 2007.

[13] M. Y. Jaber and S. K. Goyal, "Coordinating a three-level supply chain with multiple suppliers, a vendor and multiple buyers," International Journal of Production Economics, vol. 116, no. 1, pp. 95-103, 2008.

[14] D. Z. Jonrinaldi and D. Z. Zhang, "An integrated production and inventory model for a whole manufacturing supply chain involving reverse logistics with finite horizon period," Omega, vol. 41, no. 3, pp. 598-620, 2013.

[15] S. S. Sana, "A collaborating inventory model in a supply chain,” Economic Modelling, vol. 29, no. 5, pp. 2016-2023, 2012.

[16] B. Pal, S. S. Sana, and K. Chaudhuri, "Three-layer supply chain-a production-inventory model for reworkable items," Applied Mathematics and Computation, vol. 219, no. 2, pp. 530-543, 2012.

[17] B. Pal, S. S. Sana, and K. Chaudhuri, "A multi-echelon supply chain model for reworkable items in multiple-markets with supply disruption," Economic Modelling, vol. 29, no. 5, pp. 1891-1898, 2012.

[18] L. E. Crdenas-Barrn and S. S. Sana, "Multi-item EOQ inventory model in a two-layer supply chain while demand varies with promotional effort," Applied Mathematical Modelling, vol. 39, no. 21, pp. 6725-6737, 2015.

[19] H. Gurnani and M. Shi, "A bargaining model for a first-time interaction under asymmetric beliefs of supply reliability," Management Science, vol. 52, no. 6, pp. 865-880, 2006.

[20] J.-B. Sheu, "Bargaining framework for competitive green supply chains under governmental financial intervention," Transportation Research Part E: Logistics and Transportation Review, vol. 47, no. 5, pp. 573-592, 2011.

[21] R. Kohli and H. Park, "A cooperative game theory model of quantity discounts," Management Science, vol. 35, no. 6, pp. 693-707, 1989.

[22] X. Gan, S. P. Sethi, and H. Yan, "Coordination of supply chains with risk-averse agents," in Supply Chain Coordination under Uncertainty, pp. 3-31, Springer, Berlin, Germany, 2011.

[23] M. Nagarajan and G. Sošić, "Game-theoretic analysis of cooperation among supply chain agents: Review and extensions," European Journal of Operational Research, vol. 187, no. 3, pp. 719-745, 2008.

[24] S. Saha, I. Nielsen, and S. S. Sana, "Effect of optimal subsidy rate and strategic behaviour of supply chain members under competition on green product retailing," Mathematical Problems in Engineering, vol. 2021, Article ID 6661103, , 2021.

[25] S. S. Sana, "A structural mathematical model on two echelon supply chain system," Annals of Operations Research, pp. 1-29, 2021.

[26] N. M. Modak, N. Modak, S. Panda, and S. S. Sana, "Analyzing structure of two-echelon closed-loop supply chain for pricing, quality and recycling management," Journal of Cleaner Production, vol. 171, pp. 512-528, 2018.

[27] K. Dey, S. Roy, and S. Saha, "The impact of strategic inventory and procurement strategies on green product design in a twoperiod supply chain," International Journal of Production Research, vol. 57, no. 7, pp. 1915-1948, 2019.

[28] C. K. Chan and B. G. Kingsman, "Coordination in a singlevendor multi-buyer supply chain by synchronizing delivery and production cycles," Transportation Research Part E: Logistics and Transportation Review, vol. 43, no. 2, pp. 90-111, 2007.

[29] C. K. Chan, Y. C. E. Lee, and S. K. Goyal, "A delayed payment method in co-ordinating a single-vendor multi-buyer supply chain," International Journal of Production Economics, vol. 127, no. 1, pp. 95-102, 2010. 